\title{
Modulation of Hair Cell Voltage Responses to Tones by Low-Frequency Biasing of the Basilar Membrane in the Guinea Pig Cochlea
}

\author{
lan J. Russell and Manfred Köss|a \\ School of Biological Sciences, University of Sussex, Falmer, Brighton, BN1 9QG, England
}

Inner (IHC) and outer (OHC) hair cell receptor potentials were recorded during stimulation with combinations of high-frequency (HF) tones and a $100 \mathrm{~Hz}$ tone burst of constant level (80 dB SPL). For frequencies at and below characteristic frequency (CF), OHC AC receptor potentials were suppressed by the $100 \mathrm{~Hz}$ tone at levels of the HF tone below about $70 \mathrm{~dB}$ SPL (the initial steep part of the AC/level function) and at levels that were frequency specific for frequencies above CF. Suppression was associated with a phase lead for frequencies at and close to the CF. For frequencies above CF, the OHC AC response was either suppressed or augmented at levels of the HF tone both below and above $70 \mathrm{~dB}$ SPL, depending on the frequency. The action of the $100 \mathrm{~Hz}$ tone on the $A C$ response/level functions was to change nonmonotonic functions into monotonic functions or vice versa. IHC DC receptor potentials were suppressed maximally at the CF and at levels and frequencies where suppression of the OHC AC response and the appearance of the IHC DC response overlapped. For levels of the HF tone above $70 \mathrm{~dB}$ SPL, the amplitude of the responses of both IHCs and OHCs to the $100 \mathrm{~Hz}$ tone are suppressed and become more symmetrical through selective attenuation of the depolarizing phase of the IHC response and the hyperpolarizing phase of the OHC response. In IHCs from insensitive preparations, the response to the $100 \mathrm{~Hz}$ tone is augmented in the presence of the HF tone, which may indicate a shift in the operating point of transduction. At frequencies about one-half an octave below the CF, the phase of the $\mathbf{1 0 0}$ Hz voltage response of OHCs but not IHCs is inverted for levels of the HF tone above about $90 \mathrm{~dB}$ SPL.

It is proposed that amplitude and phase changes in the response to the HF tone due to the presence of the $100 \mathrm{~Hz}$ tone are the result of changes in OHC feedback processes and in the mode of movement of the interface between OHC stereocilia and tectorial membrane. The Interaction between the responses to $\mathrm{HF}$ and $100 \mathrm{~Hz}$ tones indicates that feedback contributes significantly to the voltage responses of OHCs throughout the frequency response range.

\footnotetext{
Received July 1, 1991; revised Oct. 28, 1991; accepted Nov. 6, 1991.

We thank Drs. C. Kros and A. Rüsch for their helpful comments on early drafts of the manuscript and Mr. J. Hartly for designing and building electronic equipment. This research was supported by grants from the MRC, Wolfson Foundation, and Hearing Research Trust.

Correspondence should be addressed to I. J. Russell, School of Biological Sciences, University of Sussex, Falmer, Brighton, BN1 9QG, England.

- Present address: Zoological Institute, University of Munich, Luisenstrasse 14, 8000 Munich 2, Germany.

Copyright $(\mathcal{C} 1992$ Society for Neuroscience $0270-6474 / 92 / 121587-15 \$ 05.00 / 0$
}

Current understanding of sensory transduction in the mammalian cochlea is dominated by the concept of a division of labor between the inner (lHC) and outer (OHC) hair cells (Davis, 1983). The role of the IHCs is to respond to the shear displacement between the tectorial membranc and the cuticular plate and to signal this information to the brainstem via impulse traffic in the auditory nerve. OHCs are believed to have a bidirectional role; they share a common property with IHCs, which is to transduce the mechanical displacements of the cochlear partition into voltage responses, and in addition, the voltage responses provide the basis for electromechanical feedback by the OHCs to the cochlear partition (Weiss, 1982; Davis, 1983). In this way, OHCs contribute to their own excitation and to that of the IHCs. The general acceptance of the concept has led to the inclusion of electromechanical feedback to the cochlea partition as an important component in models of transduction and frequency tuning in the cochlea (Kim et al., 1980; Mountain et al., 1983).

The concept of bidirectional transduction in the cochlea has emanated from measurements of sound-evoked otoacoustic emissions, hair cell voltage responses and auditory nerve activity to perturbation of cochlear function through selective destruction of $\mathrm{OHCs}$, excitation of the medial efferent system, and electrical stimulation of the cochlear partition (e.g., Kemp, 1978; Mountain, 1980; Siegel and Kim, 1982; Brown et al., 1983; Ruggero and Rich, 1991; see Dallos, 1988, for a review). More recently, the discovery of $\mathrm{OHC}$ electromotility has contributed to the concept (Brownell et al., 1985). Early measurements of $\mathrm{OHC}$ motility have led to the conclusion that this is a robust, linear transformation of the OHC voltage response (Ashmore, 1987). Recent findings indicate that $\mathrm{OHC}$ electromotility is nonlinear (Santos-Sacchi, 1989), and in response to sinusoidal transcellular current stimulation, $\mathrm{OHCs}$ generate $\mathrm{AC}$ length changes about a net DC length change (Evans et al., 1988, 1991), features reflected in the tone-evoked voltage responses that have been recorded from OHCs in situ (Dallos et al., 1982; Russell et al., 1986). The current-induced DC length changes are metabolically vulnerable and sensitive to small changes in $\mathrm{OHC}$ membrane potential (Evans et al., 1991). These results correspond with the discovery that temporary threshold shift in sensitivity of the cochlea following a period of intense acoustic stimulation (TTS) is associated with depolarization of the OHCs (Cody and Russell, 1985, 1989). On the basis of this observation and the consistent finding that OIICs in the basal turn of the cochlea do not generate DC voltage responses to high frequency (HF) tones at low and moderate sound levels (Russell et al., 1986; Cody and Russell, 1987), it has been proposed that by mini- 
mizing the DC component of the receptor potential, OHCs optimize electromechanical feedback by keeping the operating point in the steepest part of the transducer function (Russell et al., 1986; Russell and Kössl, 1991). In the experiments reported in this article, the responses of OHCs and IHCs to HF tones at different levels and frequencies about the characteristic frequency $(\mathrm{CF})$ are altered by low-frequency displacements of the basilar membrane caused by the simultaneous presentation of an $80 \mathrm{~dB}$ SPL, $100 \mathrm{~Hz}$ tone. The effect of the $100 \mathrm{~Hz}$ tone on the $\mathrm{HF}$ tone is highly dependent on the level and frequency of the $\mathrm{HF}$ tone. Furthermore, the $\mathrm{IHC}$ and $\mathrm{OHC}$ voltage responses to the $100 \mathrm{~Hz}$ tone are altered in ways that depend on the frequency and level of the HF tones. It is proposed that amplitude and phase changes in hair cell responses to $\mathrm{HF}$ tones due to the $100 \mathrm{~Hz}$ tone are the result of changes in OHC feedback processes and in the mode of movement of the interface between the $\mathrm{OHC}$ stereocilia and the tectorial membrane. The results presented here also indicate that reverse transduction is a nonlinear phenomenon that contributes to the voltage responses of OHCs throughout the frequency range.

Some of the data presented in this article have been published in the proceedings of a meeting (Kössl and Russell, 1990).

\section{Materials and Methods}

Animal preparation and recording. The experimental techniques employed in the experiments described in this article are identical to those described in earlier reports (Cody and Russell, 1987; Russell and Kössl, 1991; Kössl and Russell, 1992). Young pigmented guinea pigs weighing 180-300 gm were used in this study. The animals were anesthetized with sodium pentobarbitone $(30 \mathrm{mg} / \mathrm{ml})$, Operidine $(1 \mathrm{mg} / \mathrm{ml})$, and Droleptan (4 mg/ml) (Evans, 1979), and a tracheal cannula was inserted. The body temperature of the guinea pig was kept at $38^{\circ} \mathrm{C}$ with a heating blanket. The heart rate was monitored through a pair of skin electrodes placed on either side of the thorax. The right cochlea was exposed through a lateral opening in the temporal bone and back illuminated by a fiber optic light guide inserted through a hole made in the basal wall of the bulla.

Micropipettes were pulled from $1 \mathrm{~mm}$ o.d. fiber-filled glass tubing and filled with $4 \mathrm{M}$ potassium acetate and $0.1 \mathrm{M} \mathrm{KCl}$. Resistances of the micropipettes ranged between 180 and $300 \mathrm{M} \Omega$ when measured in the perilymph of the scala tympani. The $\mathrm{Ag}-\mathrm{AgCl}$ electrode was inserted in the neck muscles.

The compound action potential (CAP) of the cochlear nerve was recorded with an electrode placed on the round window.

Signal analysis. The measurement of high-frequency voltage responses such as those displayed in Figures 3, 7, and 8-13 was performed by means of a two-channel lock-in amplifier (EG \& G, Princeton, model $5210)$ referenced to the driving voltage for the high-frequency tone. The time constant was usually set at $3 \mathrm{msec}$ with a $6 \mathrm{~dB} /$ octave slope. The records shown in Figures 1-6 were also low-pass filtered at $24 \mathrm{~dB}$ /octave at $3 \mathrm{kHz}$ to eliminate $\mathrm{AC}$ voltage responses to the high-frequency tones and sampled at $0.1-0.5 \mathrm{msec}$ intervals for storage and analysis on a microcomputer (NTS). Signals from the in-phase and quadrature channels of the lock-in amplifiers were also sampled at $0.1-0.5 \mathrm{msec}$ intervals, and the phase and magnitude of the AC component of the voltage signal were computed either on line or from data stored on disk by the microcomputer.

Acoustic stimulation. Sound was delivered to the tympanic membrane by a calibrated closed acoustic system. High-frequency tones were delivered through a Bruel and Kjaer 3134 1/2 inch condenser microphone, and a Beyer DT48 dynamic ear phone was used to deliver the $100 \mathrm{~Hz}$ tones. Continuous tones and tone bursts were presented at known sound pressure level, expressed in this article in $\mathrm{dB}$ SPL (sound pressure level; $\mathrm{dB}$ re $2 \times 10^{-5} \mathrm{~Pa}$ ).

Experimental procedures. The experimental procedures were adopted from those set out in detail elsewhere (Cody and Russell, 1987; Russell and Kössl, 1991). In this series of experiments, the criterion for a sensitive preparation was one in which the change in the CAP threshold audiogram following exposure of the basilar membrane was less than $10 \mathrm{~dB}$. The frequency compensation applied to phasic voltage responses recorded through the micropipette was based on the analysis of the frequency response of the recording system according to the method that was first described by Baden-Kristensen and Weiss (1983) (see Cody and Russell, 1987). On the basis of this analysis, the recording system was treated as a single-pole low-pass filter with corner frequencies between 1 and $3.5 \mathrm{kHz}$. In some experiments, the characteristic frequencies (CF) of the hair cells were determined from the peak voltage response to low-level tones that were swept through the frequency response range of the hair cell.

\section{Results}

\section{$O H C$ responses to combined $\mathrm{HF}$ and $100 \mathrm{~Hz}$ tones}

Intracellular and extracellular receptor potentials were recorded from $\mathrm{OHCs}$ to $100 \mathrm{~Hz}$ tones presented simultaneously with $\mathrm{HF}$ tones. The intracellular receptor potentials recorded from an $\mathrm{OHC}$ (16 kHz CF and $-60 \mathrm{mV}$ resting membrane potential) are shown in Figure 1, in response to combinations of $\mathrm{HF}$ tones at $12 \mathrm{kHz}, 16 \mathrm{kHz}(\mathrm{CF})$, and $24 \mathrm{kHz}$. For levels of the $12 \mathrm{kHz}$ tone below $75 \mathrm{~dB}$ SPL, the $100 \mathrm{~Hz}$ receptor potentials are apparently unchanged by the increasing level of the HF tone. At higher levels, the $100 \mathrm{~Hz}$ response is attenuated. This attenuation is maximal at about $80 \mathrm{~dB}$ SPL when the $\mathrm{OHC}$ generates a DC response to the HF tone. Above $90 \mathrm{~dB}$ SPL, the amplitude of the $100 \mathrm{~Hz}$ response increases again but the phase is now reversed by $180^{\circ}$. This is apparent in Figure 1 but is more clearly observed in the magnified traces shown in Figure 2. In Figure 3 the magnitudes of the $\mathrm{AC}$ response to the $\mathrm{HF}$ tones (top row) and the phase of the $A C$ response to the HF tones (second row) are compared with the DC response to the HF tone (third row) and the peak positive and peak negative voltage responses to the $100 \mathrm{~Hz}$ tone (bottom row). From Figure 3 it can be seen that the phase reversal of the $100 \mathrm{~Hz}$ response is correlated with saturation of the $\mathrm{HF} \mathrm{AC}$ response, phase reversal of the $\mathrm{AC}$ response, and the appearance of the $\mathrm{DC}$ response to the $12 \mathrm{kHz}$ tone. The phase reversal of the $100 \mathrm{~Hz}$ response was consistently associated with the presentation of tones at frequencies about one-half an octave below the CF and at levels above $90 \mathrm{~dB}$ and was observed each time it was looked for in $\mathrm{OHC}$ responses in more than 20 preparations. At CF, the SPL required to elicit the DC response and the threshold for suppression of the 100 $\mathrm{Hz}$ tone were both greater than at lower frequencies (see Fig. 1). Within the range of levels of the CF tone that was employed, phase reversal of the $100 \mathrm{~Hz}$ response was not observed. This might be because the DC response generated at these stimulus levels are smaller for tones at frequencies close to and above CF than for tones below CF. DC responses were not elicited by tones at $24 \mathrm{kHz}$ at levels up to $97.5 \mathrm{~dB}$ SPL, although leveldependent phase reversal of the $24 \mathrm{kHz}$ AC response does take place (see Fig. 3) and the $100 \mathrm{~Hz}$ responses were unchanged by the addition of the HF tone (Figs. 1, 3).

Attenuation of the HF response results in a lateral shift in the HF AC/level functions (top row of Fig. 3). For CF tones at levels below $30 \mathrm{~dB}$ SPL, the slopes of the control and suppressed level functions are similar and close to 1. For levels between 30 and $70 \mathrm{~dB}$ SPL, the slope of the suppressed function remains close to 1 but the control is less steep and the function develops the slow saturation (compression), which is typical of magnitude/ level functions measured for basilar membrane and hair cell responses (e.g., Rhode, 1971; Russell and Sellick, 1978; Sellick et al., 1982).

Extracellular responses were recorded adjacent to OHCs (not shown) that were essentially identical to those recorded intracellularly, but the amplitudes of the extracellular $100 \mathrm{~Hz}$ re- 
$12 \mathrm{kHz}$

$16 \mathrm{kHz}$
$24 \mathrm{kHz}$

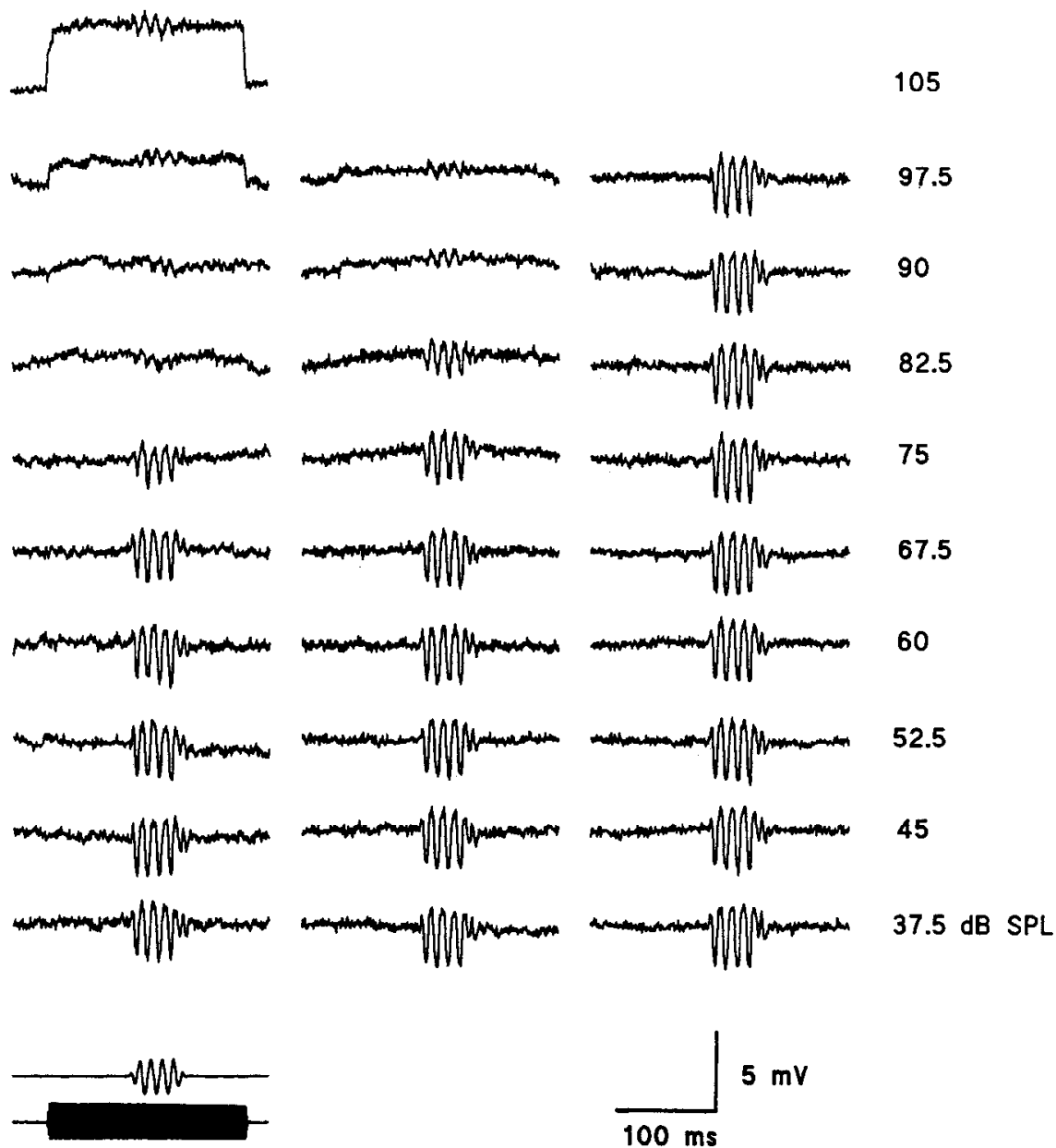

Figure 1. Intracellular voltage responses of an OHC to a combination of $80 \mathrm{~dB} \mathrm{SPL}, 100 \mathrm{~Hz}$ tones and tones at $12 \mathrm{kHz}, 16 \mathrm{kHz}(\mathrm{CF})$, and $24 \mathrm{kHz}$ at the levels shown to the right. The waveform of the $100 \mathrm{~Hz}$ tone and the envelope of the $\mathrm{HF}$ tone are shown at the bottom left. Resting membrane potential, $-68 \mathrm{mV}$. The voltage responses are low-pass filtered at $3 \mathrm{kHz}$. sponses and the OHC DC responses were $20-50 \%$ of those recorded intracellularly from $\mathrm{OHCs}$ in the same preparation.

\section{$I H C$ responses to combined $I I F$ and $100 \mathrm{~Hz}$ tones}

Both the shape and the amplitude of the $100 \mathrm{~Hz}$ response depend on the level and the frequency of the HF tone (see Figs. 4, 5). When presented together with the $13 \mathrm{kHz}$ tone, the $100 \mathrm{~Hz}$ response remains unchanged until the level of the $13 \mathrm{kHz}$ tone is sufficient to elicit a DC response ( $57 \mathrm{~dB}$ SPL). For levels of the $13 \mathrm{kHz}$ tone above $57 \mathrm{~dB}$ SPL, the $100 \mathrm{~Hz}$ response appears superimposed on the DC response to the $13 \mathrm{kHz}$ tone, and declines in amplitude and appears more symmetrical largely as a consequence of the selective attenuation of the depolarizing phase. In contrast, the DC response to the $13 \mathrm{kHz}$ tone does not appear to be strongly suppressed by the $100 \mathrm{~Hz}$ tone.

The interaction between the $100 \mathrm{~Hz}$ tone and the $\mathrm{HF}$ tone at the CF of the cell ( $18 \mathrm{kHz}$, Fig. $4 ; 19.5 \mathrm{kHz}$, Fig. 5) is complex and level dependent. At low levels of the CF tone, the response to the $100 \mathrm{~Hz}$ tone appears to have a strong first-order harmonic (2f) component and to be hyperpolarizing relative to the $\mathrm{DC}$ response to the $\mathrm{CF}$ tone. At levels of the $\mathrm{CF}$ tone above about $60 \mathrm{~dB}$ SPL, the $100 \mathrm{~Hz}$ response becomes attenuated and appears to ride on the $\mathrm{DC}$ response to the $\mathrm{CF}$ tone. At levels below

\section{$12 \mathrm{kHz}$}

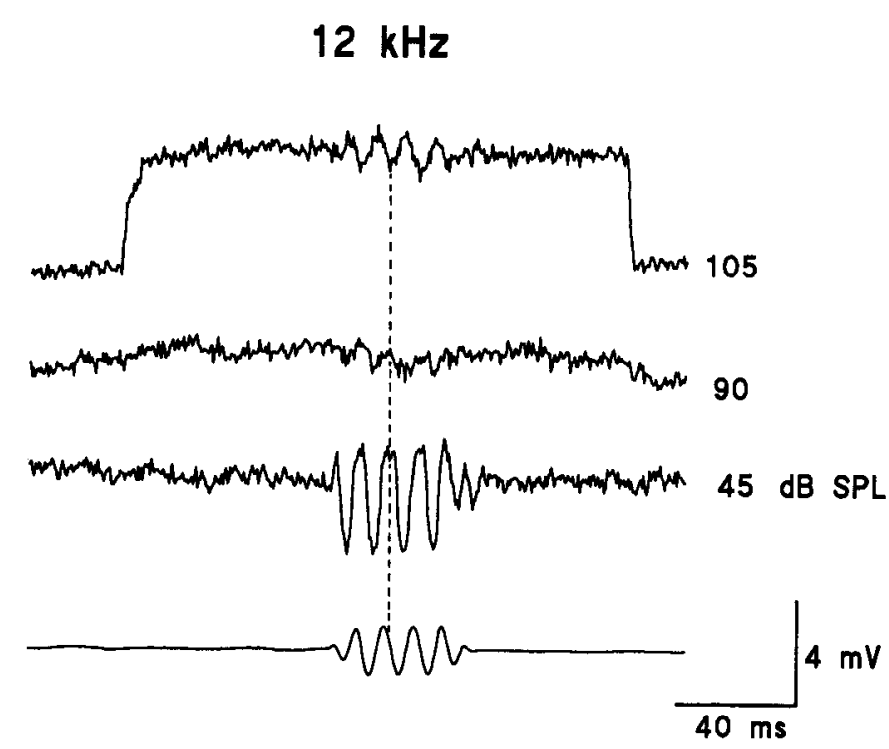

Figure 2. Reversal in phase of the intracellular $\mathrm{OHC}$ responses shown in Figure 1 to the $100 \mathrm{~Hz}$ tone when the level of the $12 \mathrm{kHz}$ tone exceeds $90 \mathrm{~dB}$ SPL. The voltage responses are low-pass filtered at $3 \mathrm{kHz}$. A broken line is drawn through the peak depolarization and hyperpolarization of the responses to the $45 \mathrm{~dB}$ SPL and the $105 \mathrm{~dB}$ SPL tones, respectively. 

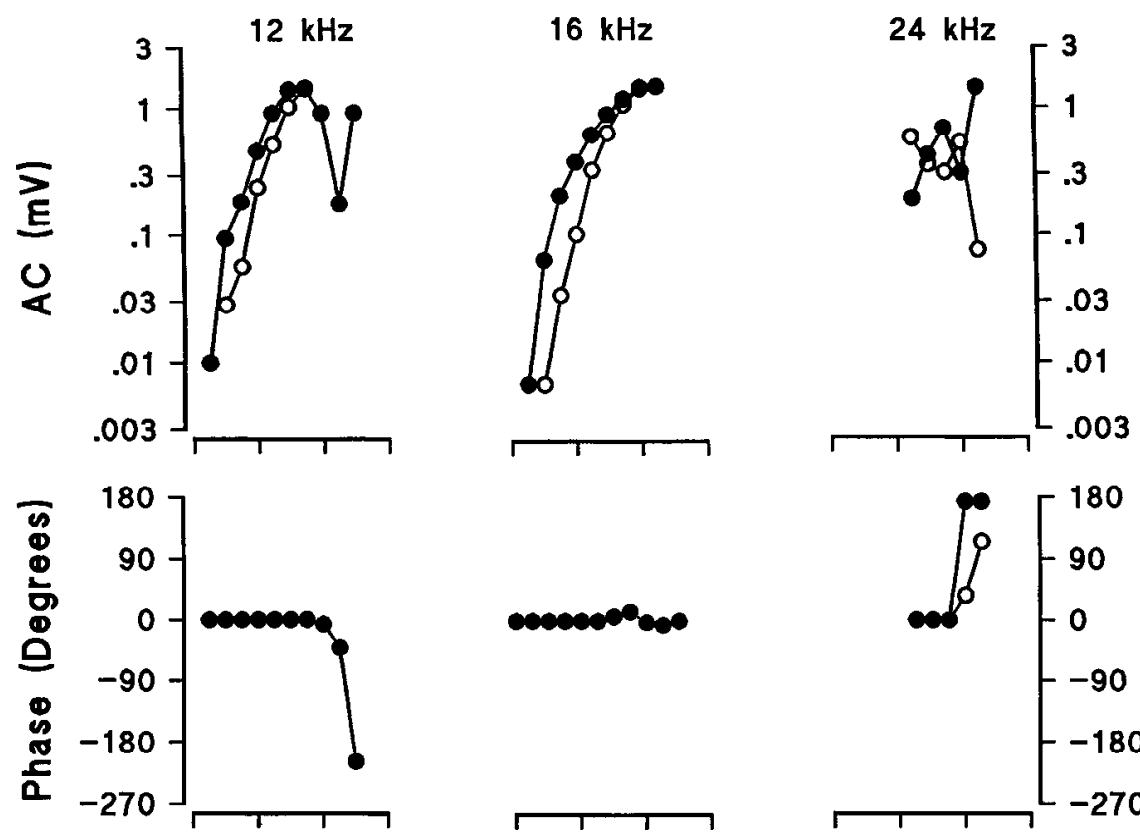

Figure 3. Level functions of the intracellular $\mathrm{OHC}$ voltage responses shown in Figure 1. HF AC voltage response (top row), phase of the HF AC voltage response (second row), DC voltage response to the HF tone (third row), and peak positive (open circles) and peak negative (solid circles) voltage responses to the $100 \mathrm{~Hz}$ tone (bottom row). In the top three rows, solid circles represent the $\mathrm{AC}$ response to the $\mathrm{HF}$ tone alone; open circles represent the AC response to the $\mathrm{HF}$ tone in combination with the $100 \mathrm{~Hz}$ tone. The magnitude of the $\mathrm{AC}$ response has been compensated for the low-pass filtering of the recording system $(3.5 \mathrm{kHz})$ but not for the OHC membrane time constant $(0.3$ msec).
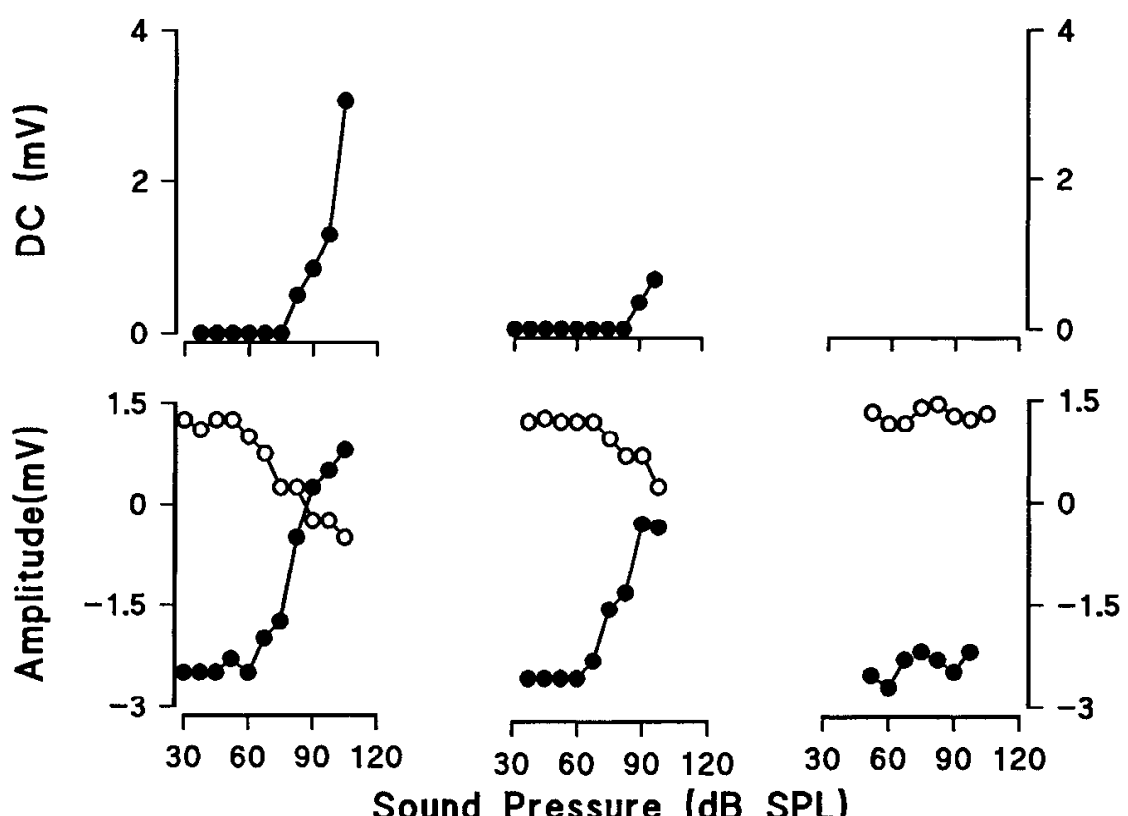

$60 \mathrm{~dB}$ SPL, this level-dependent interaction between the two tones results in an increase in the peak-to-peak amplitude of the $100 \mathrm{~Hz}$ response. A possible explanation of the apparent augmentation and frequency doubling of the response to the 100 $\mathrm{Hz}$ tone is that the observed voltage response is the sum of an excitatory response to the $100 \mathrm{~Hz}$ tone and inhibition of the $\mathrm{DC}$ response to the $18 \mathrm{kHz}$ tone by the $100 \mathrm{~Hz}$ tone during basilar membrane displacements toward both the scala media and the scala tympani. Evidence in support of this explanation is illustrated in Figure 6. At the bottom of the figure is a representation of the lime course of the $18 \mathrm{kHz}$ tone and the 80 dB SPL $100 \mathrm{~Hz}$ tone, which has been shifted by $90^{\circ}$ to take into account the observation that basilar membrane displacement is proportional to stapes velocity at low frequencies in the basal turn of the guinea pig cochlea (Wilson and Johnstone, 1975). The lower trace is the response to the $100 \mathrm{~Hz}$ tone alone, which by comparison with the representation (broken lines) shows that the peaks of the response correspond with zero basilar displacement or maximum basilar membrane velocity and excitation is associated with maximum basilar membrane velocity toward scala tympani. To determine changes of the DC potential in the presence of the $100 \mathrm{~Hz}$ tone, the response to the $100 \mathrm{~Hz}$ tone alone was subtracted from the upper trace, which shows the combined $100 \mathrm{~Hz}$ and $18 \mathrm{kHz}$ response. The resulting trace is labeled as the difference. The justification for this manipulation is that the $\mathrm{OHC}$ responses to the $100 \mathrm{~Hz}$ tone, and presumably the mechanical input to the IHCs at this frequency, remain unchanged by the simultaneous presence of the $\mathrm{CF}$ tone for levels of the CF tone below $67.5 \mathrm{~dB}$ SPL (see Fig. 1). Subtraction of the $100 \mathrm{~Hz}$ response from the combined response reveals that the apparent modulation of the IHC DC response to the $\mathrm{CF}$ tone at twice the frequency of the $100 \mathrm{~Hz}$ tone may be largely 
$13 \mathrm{kHz}$
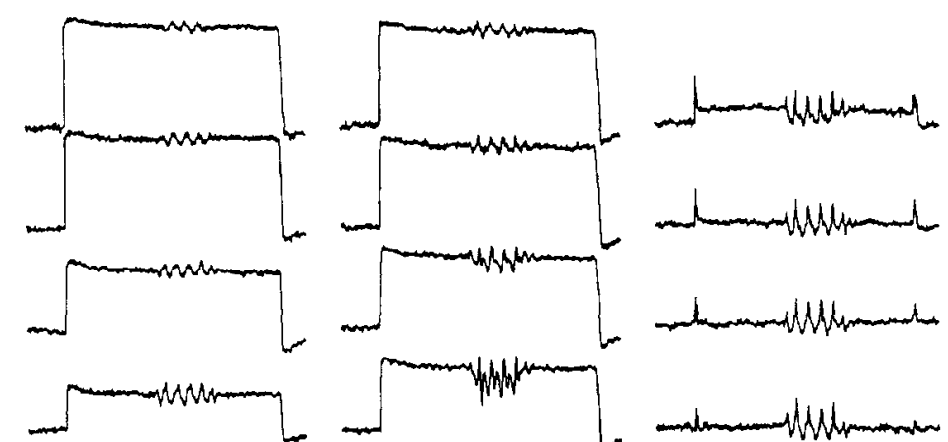

94.5

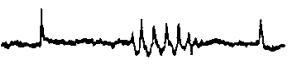

87
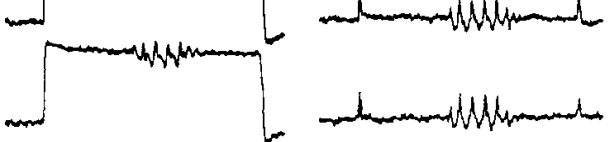

79.5
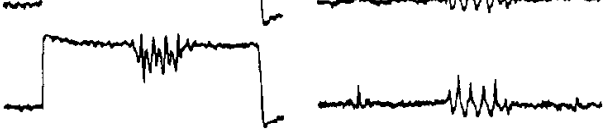

72
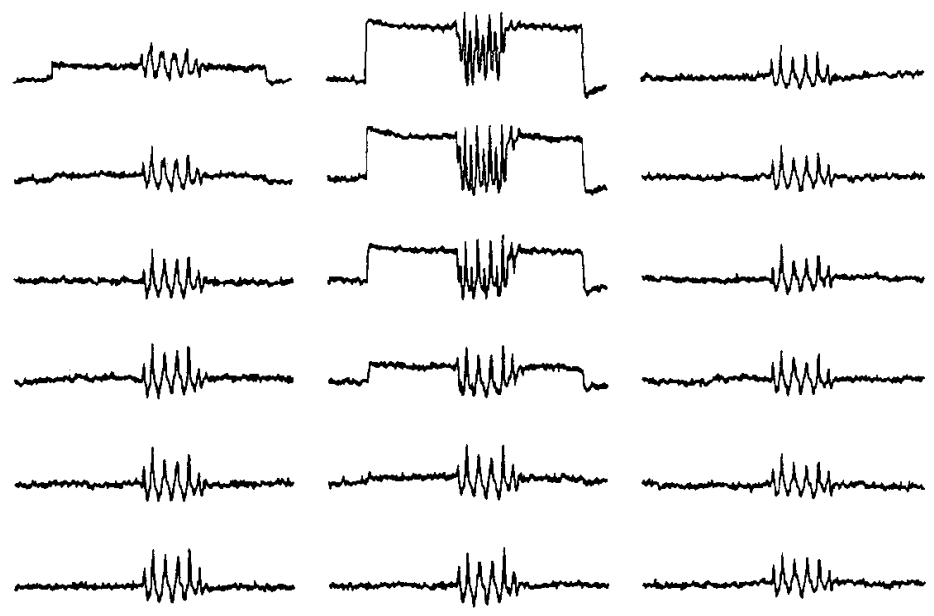
2.
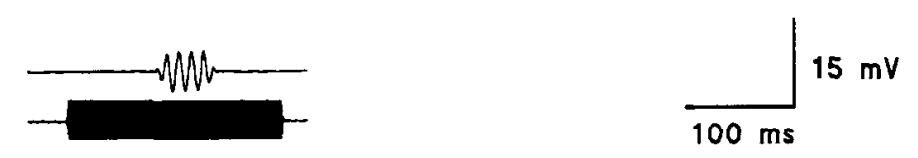

\begin{abstract}
Figure 4. Intracellular voltage responses of an IHC to a combination of $80 \mathrm{~dB}$ SPL, $100 \mathrm{~Hz}$ tones and tones at $13 \mathrm{kHz}, 18 \mathrm{kHz}(\mathrm{CF})$, and $24 \mathrm{kHz}$ at the levels shown to the right. The waveform of the $100 \mathrm{~Hz}$ tone and the envelope of the HF tone are shown at the bottom left. Resting membrane potential, $-45 \mathrm{mV}$. The voltage responses are low-pass filtered at $3 \mathrm{kHz}$.
\end{abstract}

due to suppression of the DC response by displacement of the basilar membrane toward both the scala media and the scala tympani. Suppression of the DC component is at a minimum during peak basilar membrane velocity (zero basilar membrane displacement) toward scala vestibuli (corresponding to the excitatory peak of the $100 \mathrm{~Hz}$ response) and during peak basilar membrane velocity toward scala tympani (corresponding to the negative peak of the $100 \mathrm{~Hz}$ response; see Fig. 6). This subtractive manipulation was performed on intracellular recordings from two further IHCs with similar results. For tones above $\mathrm{CF}$, for example, $24 \mathrm{kHz}$ (Fig. 4), the waveform of the response to the $100 \mathrm{~Hz}$ tone remains unchanged with increasing levels of the $24 \mathrm{kHz}$ tone until the level of the $24 \mathrm{kHz}$ tone exceeds 87 $\mathrm{dB}$ SPL, which is close to the detection threshold for the DC response to the $24 \mathrm{kHz}$ tone. At this level, a small but noticeable $2 f$ component is present in the $100 \mathrm{~Hz}$ response, which may indicate suppression of the $A C$ response associated with the 100 $\mathrm{Hz}$ tone. Thus, through phase-dependent suppression of the DC response to the $\mathrm{HF}$ tone at frequencies at and above $\mathrm{CF}$, the response to the $100 \mathrm{~Hz}$ tone appears to double in frequency and to grow in amplitude in a nonmonotonic and level-dependent manner by reaching a maximum at levels of the HF tone close to $60 \mathrm{~dB}$ SPL and then declining (see top row in Fig. 7).
$\mathrm{HF}$ AC/level functions for the IHC are shown in Figure 7 (middle row). At $13 \mathrm{kHz}$, which is about one-half an octave below the $\mathrm{CF}$, the $\mathrm{AC} /$ level function is a nonmonotonic function similar to those recorded from OHCs. The "notch" in the function is also associated with a phase reversal of the $13 \mathrm{kHz} \mathrm{AC}$ response (see bottom row), but in contrast to thc $\mathrm{OHC}$ responses, the $100 \mathrm{~Hz}$ response is not reversed at high levels of the $13 \mathrm{kHz}$ response (Fig. 4). Suppression of the HF AC and DC responses is associated with a lateral shift in the AC/level functions. At $\mathrm{CF}$, the extent of the shift is the width of the compressive region of the control $\mathrm{AC} /$ level function. At frequencies close to and above the $\mathrm{CF}$, the phase of the HF AC response is altered during suppression by the $100 \mathrm{~Hz}$ tone. At CF, for the IHC shown in Figure 7 , the phase undergoes a lag/lead transition such that suppression of the response for levels of the $\mathrm{CF}$ tone below the point of confluence between the control and suppressed curves (70 dB SPL) is associated with a slight phase lag (bottom row in Fig. 7). For CF tone levels above $70 \mathrm{~dB}$ SPL, the action of the $100 \mathrm{~Hz}$ tone is to cause a phase lead in the $\mathrm{AC}$ response to the $\mathrm{CF}$ tone, although the $100 \mathrm{~Hz}$ tone does not cause suppression. Similar observations were obtained in three other preparations. In comparison with the responses of $\mathrm{OHCs}$, the $100 \mathrm{~Hz}$ tone causes IHC AC responses to tones above CF (e.g., $24 \mathrm{kHz}$, 


\section{$19.5 \mathrm{kHz}$}

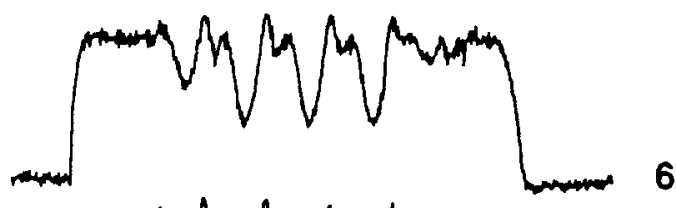

64
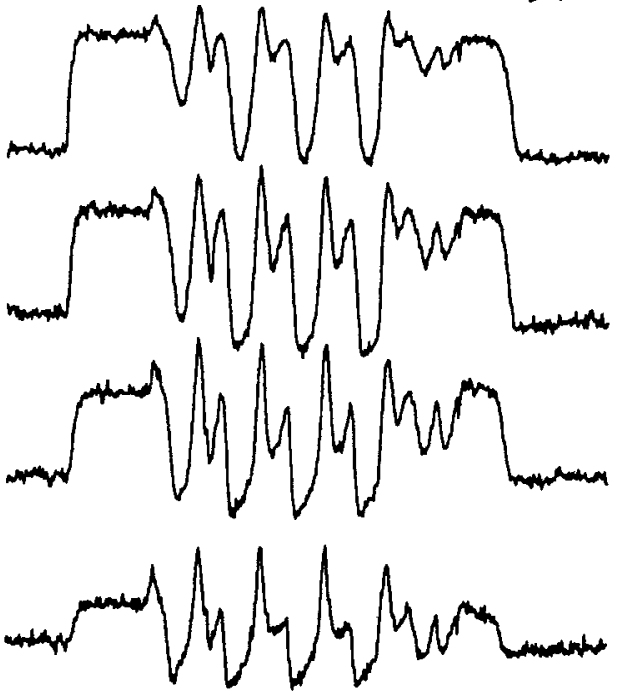

28

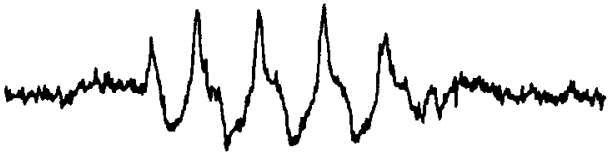

19

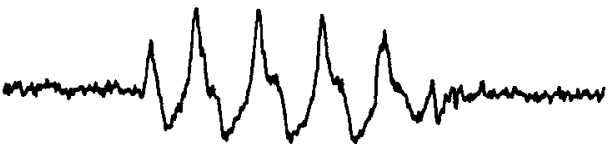

10 dB SPL $10 \mathrm{mV}$

$20 \mathrm{~ms}$

Figure 5. Intracellular voltage responses of an IHC to a combination of $80 \mathrm{~dB} \mathrm{SPL}, 100 \mathrm{~Hz}$ tones and a tone at $19.5 \mathrm{kHz}$ (CF) at the levels shown to the right. The waveform of the $100 \mathrm{~Hz}$ tone and the envelope of the HF tone are shown at the bottom. Resting membrane potential, $-40 \mathrm{mV}$. The voltage responses are low-pass filtered at $3 \mathrm{kHz}$.

Fig. 7) to be suppressed or augmented at high but not at low levels of the $24 \mathrm{kHz}$ tone and introduces phase changes at all levels of the $24 \mathrm{kHz}$ tone regardless of whether or not the magnitude of the $24 \mathrm{kHz} \mathrm{AC}$ response has been changed.

\section{Level-dependent interaction between the responses to $100 \mathrm{~Hz}$} tones and CF tones recorded from insensitive hair cells

In addition to the effects described above, which are from relatively sensitive hair cells, frequency- and level-dependent changes have been recorded from IHCs in cochleas that have

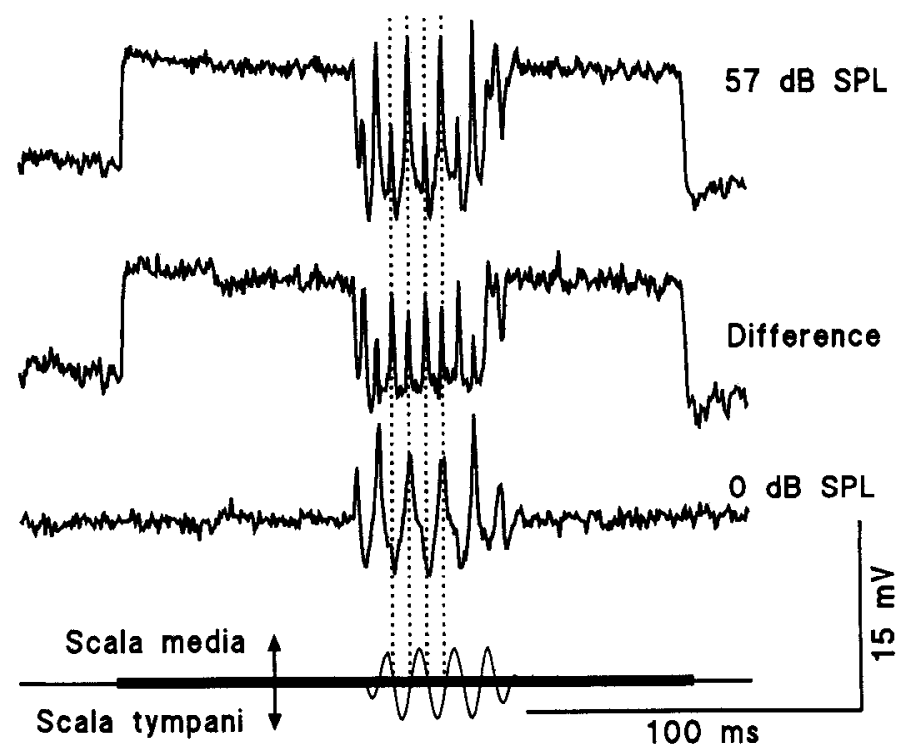

Figure 6. Suppression of the DC response of an IHC (responses shown in Fig. 4) to a $57 \mathrm{~dB}$ SPL tone at $18 \mathrm{kHz}$ (CF) by the $100 \mathrm{~Hz}, 80 \mathrm{~dB}$ SPL tone (Difference trace). This trace was obtained by subtracting the response to the $100 \mathrm{~Hz}, 80 \mathrm{~dB}$ SPL tone alone $(0 \mathrm{~dB} S P L)$ from the response to the combination of $100 \mathrm{~Hz}$ and $18 \mathrm{kHz}$ tones $(57 \mathrm{dBSPL}$ ). $57 d B S P L$ and $0 \mathrm{~dB} S P L$ refer to the levels of the $18 \mathrm{kHz}$ tone. The representation at the bottom shows the sound pressure recorded at the external auditory meatus to the $100 \mathrm{~Hz}$ tone. The thick line indicates the time course of the $18 \mathrm{kHz}$ tone. The vertical broken lines are drawn through the positive and negative peaks of the IHC voltage response to the $100 \mathrm{~Hz}$ tone.

sustained damage during preparation resulting in a threshold loss of about $20 \mathrm{~dB}$ SPL at the CF of the IHC. Responses to $100 \mathrm{~Hz}$ recorded from these hair cells are also augmented and hyperpolarized by the presence of a CF tone, but the strong $2 f$ component in the low-frequency response is absent. In another preparation, where the loss in cochlear sensitivity during preparation was about $30 \mathrm{~dB}$ SPL at the CF of the IHC, the response to the $80 \mathrm{~dB}$ SPL, $100 \mathrm{~Hz}$ tone alone was smaller than that from sensitive IHCs ( $3 \mathrm{mV}$ compared with about $10 \mathrm{mV})$ and the waveform of the $100 \mathrm{~Hz}$ response was hyperpolarized so that it appeared more symmetrical than usual (see lower traces in Fig. 8A). With simultaneous presentation of a tone at CF (14 $\mathrm{kHz}$ ), the amplitude of the $100 \mathrm{~Hz}$ response was increasingly augmented with increasing levels of the CF tone. The effect of the simultaneous presentation of swept HF tones from $3 \mathrm{kHz}$ to $30 \mathrm{kHz}$ at levels between 40 and $79.3 \mathrm{~dB}$ SPL on the magnitude of the $100 \mathrm{~Hz}$ response recorded from this IHC is shown in Figure $8 B$, where it can be seen that maximum augmentation of the $100 \mathrm{~Hz}$ response occurs at the CF. These observations may indicate that in this insensitive cochlea, the stereocilia of the IHC may be biased in a way that reduces the response amplitude to the $100 \mathrm{~Hz}$ tone alone, and only through $\mathrm{HF}$ stimulation at high levels is the operating point of the transducer function returned to a position where larger responses to the $100 \mathrm{~Hz}$ tone are generated.

Suppression of $O H C A C$ voltage responses to $H F$ tones at and below the $\mathrm{CF}$ by $100 \mathrm{~Hz}$ tones

When presented together with a HF tone at frequencies at the $\mathrm{CF}$ and within about an octave below it, the $100 \mathrm{~Hz}$ tone suppresses the $\mathrm{OHC} \mathrm{AC}$ response to the $\mathrm{HF}$ tone. This suppression 

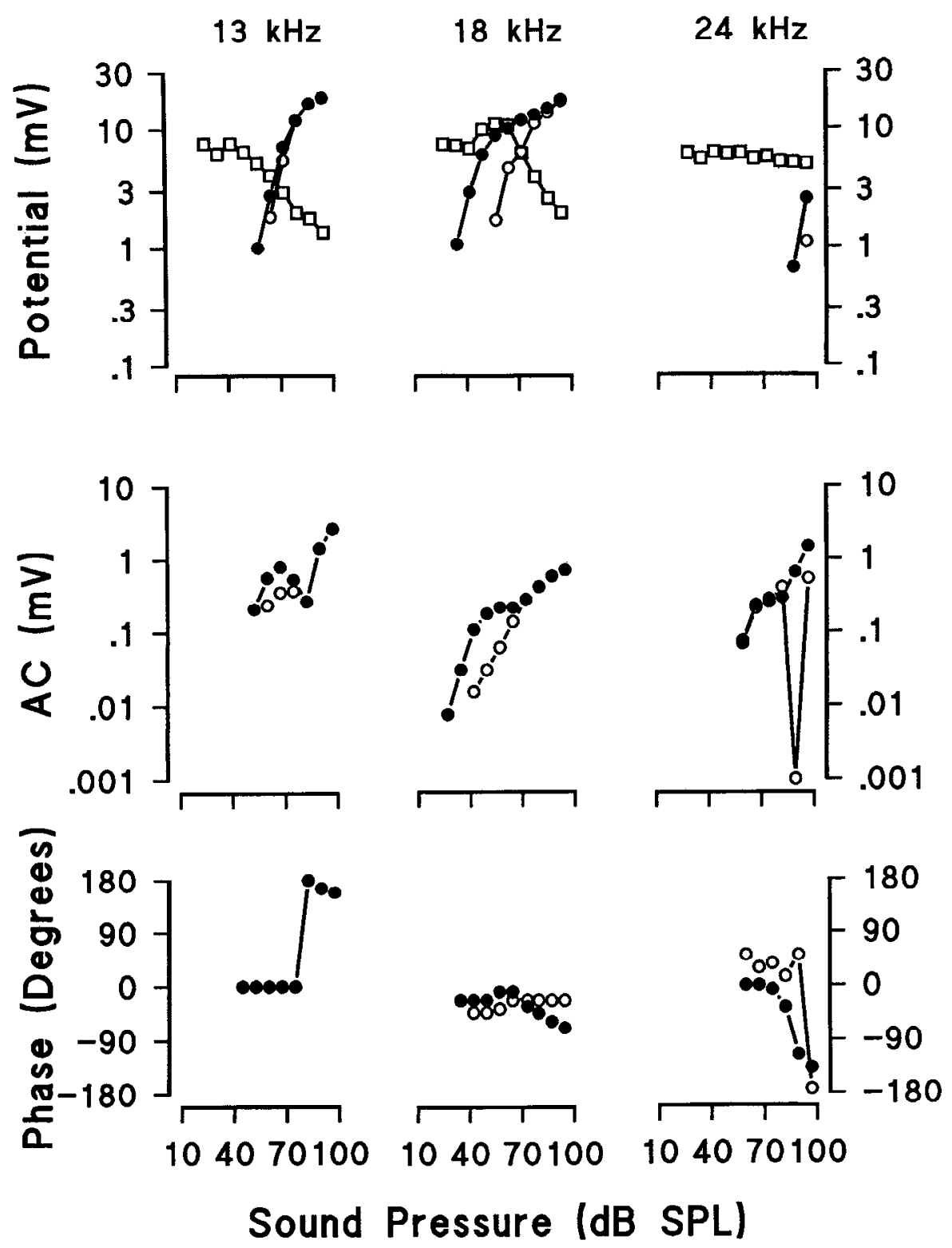

Figure 7. Level functions based on the intracellular IHC voltage responses shown in Figure 4. Top row, DC response to the HF tone (solid circles), DC response to the $\mathrm{HF}$ tone in combination with the $100 \mathrm{~Hz}$ tone (open circles), and Peak-to-peak amplitude of the voltage response to the $100 \mathrm{~Hz}$ tone in combination with the HF tone (open squares). Middle row, $\mathrm{AC}$ response to the $\mathrm{HF}$ tone (solid circles) and $\mathrm{AC}$ response to the HF tone in combination with the $100 \mathrm{~Hz}$ tone (open circles). Bottom row, Phase of the AC response to the $\mathrm{HF}$ tone (solid circles) and phase of the $A C$ response to the HF tone in combination with the $100 \mathrm{~Hz}$ tone (open circles). The magnitude of the $\mathrm{AC}$ response has been compensated for the low-pass filtering of the recording electrode $(3.5 \mathrm{kHz})$ but not for the IHC membrane time constant $(0.6 \mathrm{msec})$.

is seen in the intracellular responses shown in Figures 3 and 9 and in the extracellular responses shown in Figures 10 and 11 , where the open symbols plot the mean effect of $100 \mathrm{~Hz}, 80 \mathrm{~dB}$ SPL tones on the magnitude and phase of the $A C$ response. The suppression of the $A C$ response reaches a maximum at the $C F$ (see Fig. 11), and it depends on the level of the HF tone (see Figs. $10,17 \mathrm{kHz} ; 11,18 \mathrm{kHz}$ ), in that it is greatest for low levels of the $\mathrm{HF}$ tones and absent when the $\mathrm{AC}$ response has saturated. For frequencies below the $\mathrm{CF}$, the phase of the $\mathrm{AC}$ response does not appear to be changed during the suppression except at the CF when the suppression is associated with a phase lead of up to $90^{\circ}$ (Figs. $10,17 \mathrm{kHz} ; 11,18 \mathrm{kHz}$ ). The suppression of the IHC DC response is also frequency and level dependent and parallels suppression of the $\mathrm{OHC} A C$ response at levels where the suppression of the $A C$ response and the manifestation of the IHC DC response overlap, that is, at $15 \mathrm{kHz}$ and above (see lower curves in Fig. 11). The suppression of the $\mathrm{AC}$ response is illustrated in greater detail in Figure $12 A$, where the thick traces represent the intracellular recordings of receptor potentials from an IHC and the thin traces represent those from an $\mathrm{OHC}$ in the same cochlea, to the combination of $100 \mathrm{~Hz}, 80$ $\mathrm{dB}$ SPL and $13 \mathrm{kHz}, 67 \mathrm{~dB}$ SPL tones. The middle traces represent the magnitude of the $\mathrm{AC}$ response to the $13 \mathrm{kHz}$ tone, and the lower traces represent the phase of the $\mathrm{AC}$ response. The ripples during suppression in the $\mathrm{AC}$ response occur at a frequency twicc that of the $100 \mathrm{~Hz}$ tonc and at precisely the same phase when recorded intracellularly from the IHC and from the $\mathrm{OHC}$. By correlating the phase of the ripples during suppression of the $\mathrm{AC}$ response by the $100 \mathrm{~Hz}$ tone with the positive and negative phase of the $\mathrm{IHC}$ and $\mathrm{OHC}$ voltage responses to the tone, it becomes apparent that maximum suppression occurs during the positive and negative peaks of the OHC receptor potential and at the zero crossing (resting membrane potential) on the depolarizing and hyperpolarizing slopes of the IHC receptor potential. Suppression is associated with a small phase lead when the $\mathrm{OHC} 100 \mathrm{~Hz}$ response is positive 


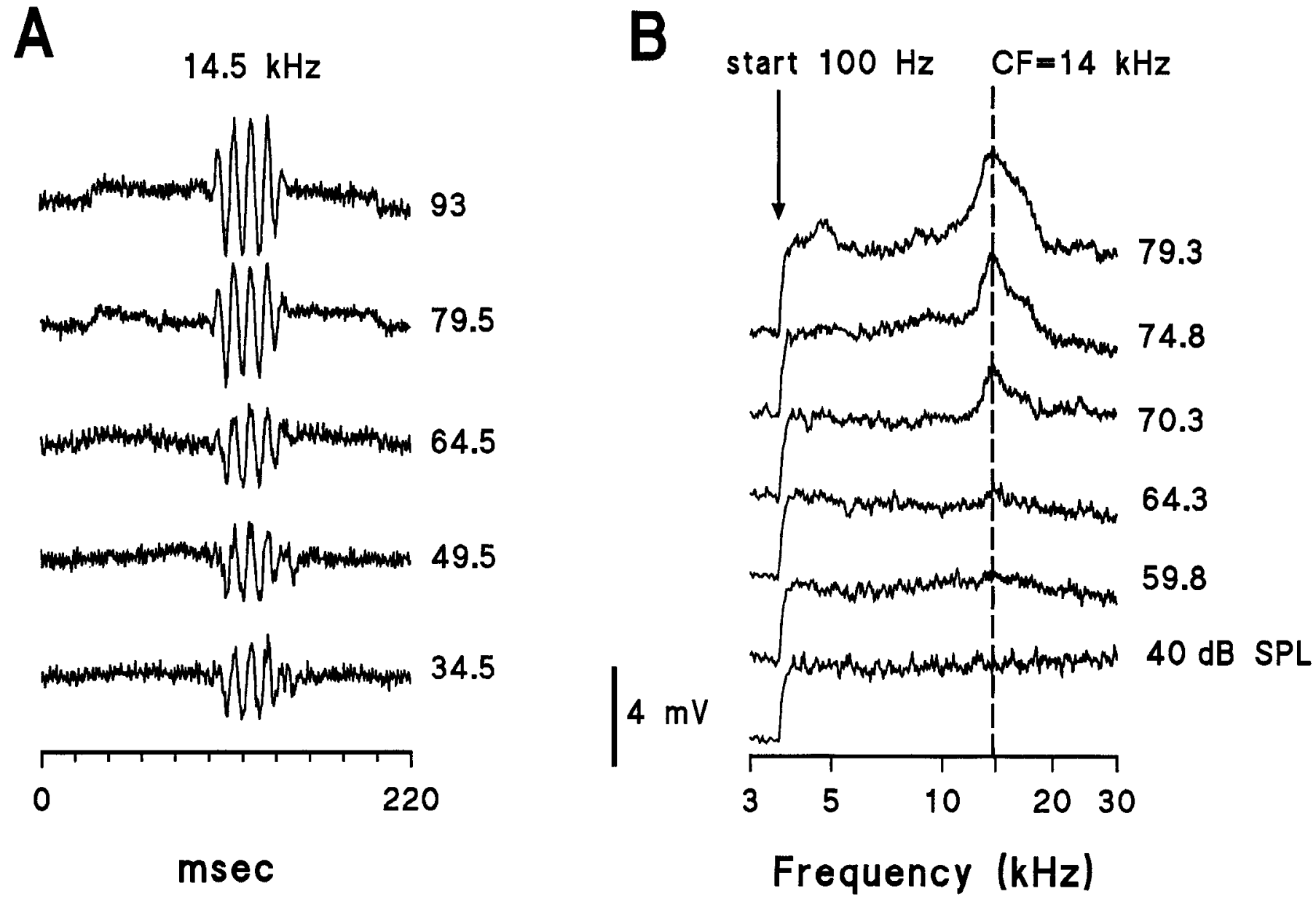

Figure 8. Intracellular responses of an insensitive IHC to combined $100 \mathrm{~Hz}, 80 \mathrm{~dB}$ SPL tones and HF tones. $A$, Voltage responses of the IHC to $100 \mathrm{~Hz}$ and $14 \mathrm{kHz}$ tones at the levels shown to the right. $B$, Magnitude of the $100 \mathrm{~Hz}$ response measured with the lock-in amplifiers as a function of the frequency and level of the HF tone when it is swept from 3 to $30 \mathrm{kHz}$. Resting membrane potential, $-40 \mathrm{mV}$.
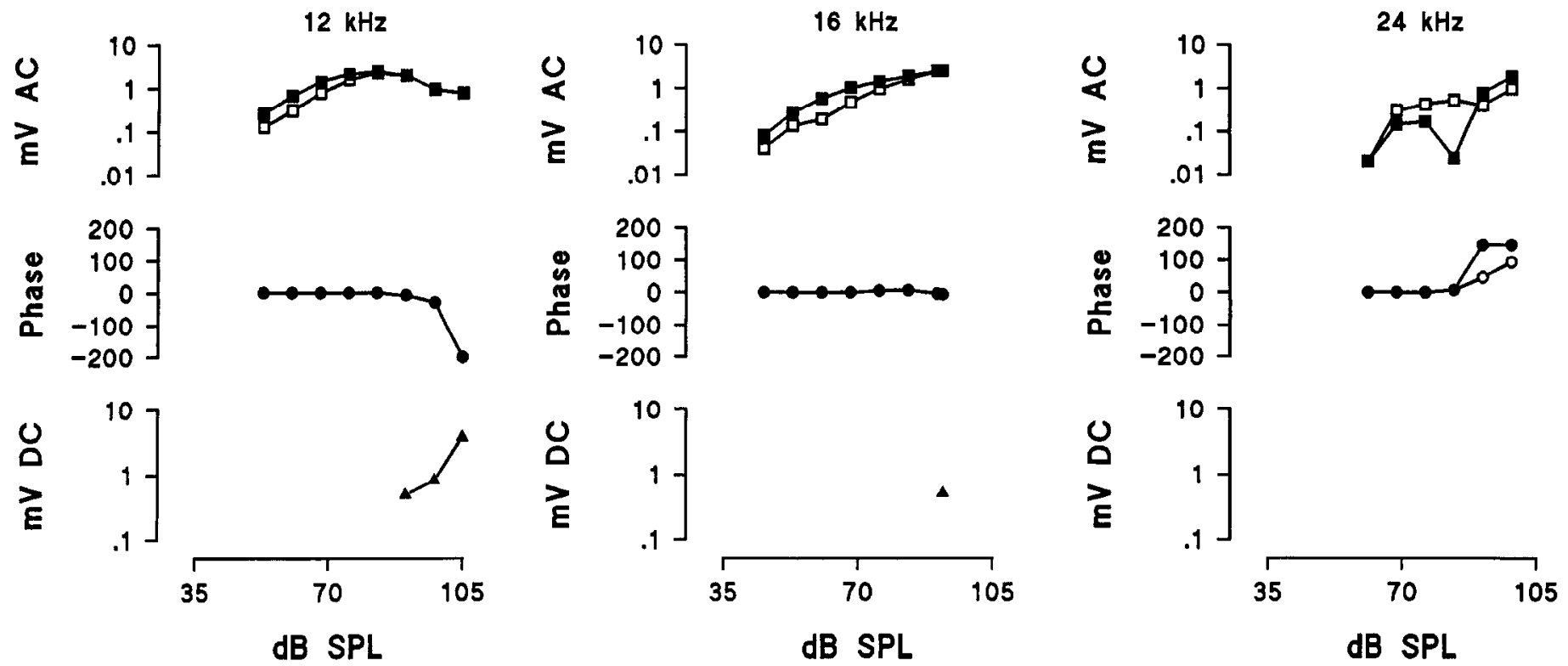

Figure 9. Tone evoked responses recorded from an $\mathrm{OHC}$ to $12 \mathrm{kHz}, 16 \mathrm{kHz}$, and $24 \mathrm{kHz}$ tones as functions of level. In each panel the magnitude of the AC response (upper curves), the phase of the AC response (middle curves), and the DC receptor potential (lower curves) is plotted as a function of tone level. Solid symbols represent the response to the HF tone alone; open symbols represent the response to the combined $100 \mathrm{~Hz}, 80 \mathrm{~dB}$ SPL tone and $\mathrm{HF}$ tone. The magnitude has been compensated for the low-pass filtering by the recording system ( $2.5 \mathrm{kHz})$ but not for the OHC membrane time constant $(0.35 \mathrm{msec})$. Resting membrane potential of $\mathrm{OHC},-70 \mathrm{mV}$; detection threshold at CF (18 kHz), $18 \mathrm{~dB}$ SPL. 

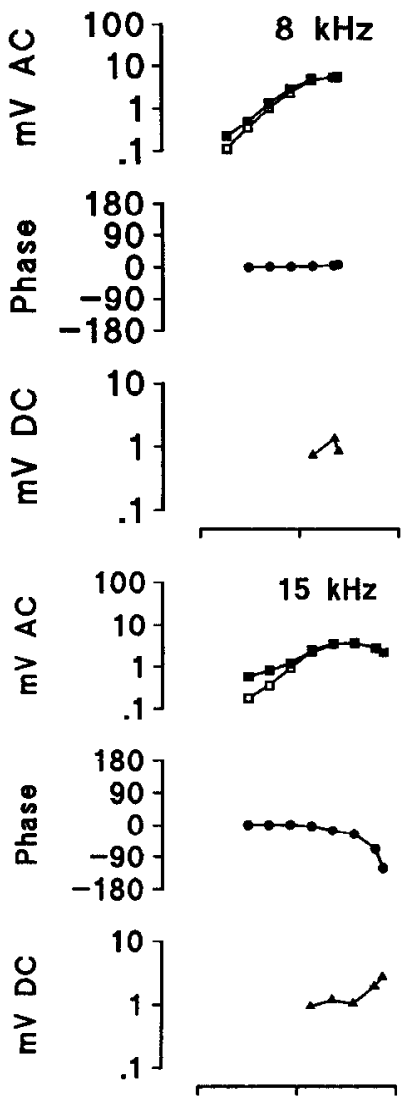

$\left.\begin{array}{lr}U & 100 \\ \gtrless & 10 \\ 1\end{array}\right]$

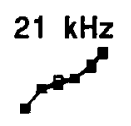

$\left.\begin{array}{rr} & 180 \\ : & 90 \\ \frac{8}{\alpha} & 0 \\ \frac{0}{\alpha} & -90 \\ & -180\end{array}\right]$
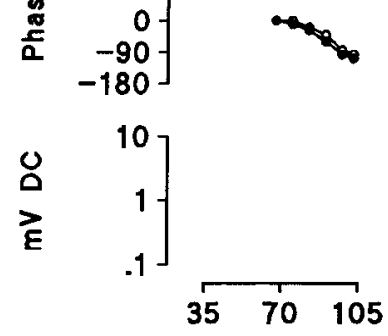
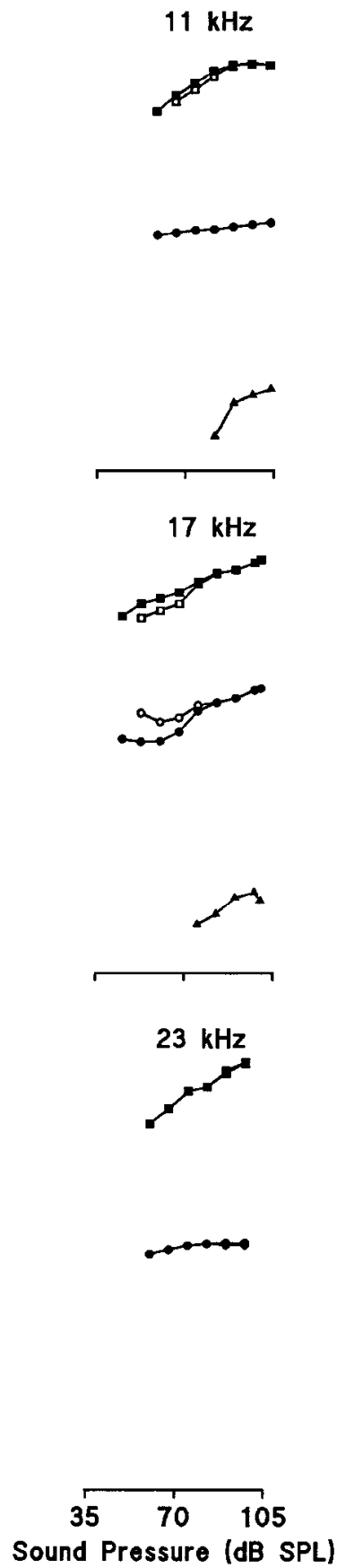
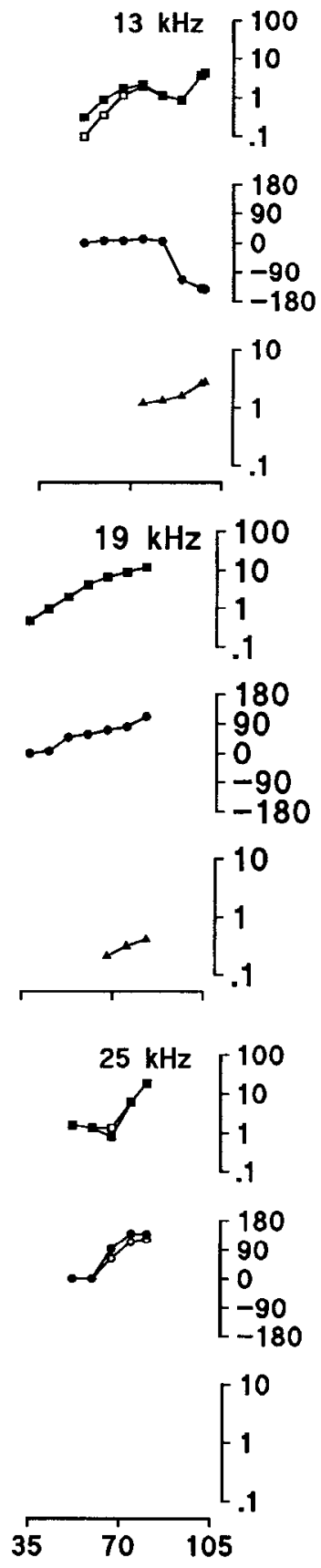

Figure 10. Magnitude, phase, and DC response/level functions based on extracellular recordings close to an $\mathrm{OHC}$ at the frequencies indicated. The $\mathrm{AC}$ potentials are assumed to reflect $\mathrm{OHC}$ $A C$ responses. The $\mathrm{DC}$ potentials are from the IHC. The magnitude of the AC response is corrected by $6 \mathrm{~dB} / \mathrm{oc}$ tave from $3.5 \mathrm{kHz}$ to compensate for the low-pass filtering due to the recording system. The curves are arranged as in Figure 9. and a phase lag when the receptor potential is negative. Thus, the frequency of the phase responses during the suppression is the same as that of the low-frequency receptor potential.

The suppression is somewhat variable and in about $80 \%$ of the records, for tones at frequencies below the CF and for nonsaturating levels, the suppression of the $\mathrm{AC}$ response increases with the duration of the $100 \mathrm{~Hz}$ tone (see Fig. 12).

Level and frequency dependence of the suppression of the $\mathrm{OHC}$ $A C$ response to tones above the $C F$ by $100 \mathrm{~Hz}$ tones

For tones at frequencies above the CF, the effect of the $100 \mathrm{~Hz}$ tone on the $\mathrm{AC}$ response to the $\mathrm{HF}$ tone is frequency and level dependent and quite complicated. The effect of the $100 \mathrm{~Hz}$ tone on the magnitude of the AC response is greatest at high levels of the HF tone and minimal or absent at low levels of the HF tone, although the $100 \mathrm{~Hz}$ tone may cause quite noticeable phase changes in the $\mathrm{AC}$ response. For example, at $20 \mathrm{kHz}$ and 40 $50 \mathrm{~dB}$ SPL (see Fig. 11), the magnitude of the AC response remains unchanged by the $100 \mathrm{~Hz}$ tone but the phase of the $\mathrm{AC}$ response leads by about $45^{\circ}$. Similar effects are illustrated in Figure $12 B$ for the intracellularly recorded responses of an $\mathrm{OHC}$ (CF, $16 \mathrm{kHz}$ ) to a combination of an $80 \mathrm{~dB}$ SPL, $100 \mathrm{~Hz}$ tone and a $23 \mathrm{kHz}$ tone at $97 \mathrm{~dB}$ SPL. The magnitude of the AC response to the $\mathrm{HF}$ tone (middle trace) is completely suppressed at the onset of the $100 \mathrm{~Hz}$ tone without a change in the phase of the AC response (lower trace). After a delay of $11 \mathrm{msec}$, the phase of the $\mathrm{AC}$ response jumps by $180^{\circ}$ and the magnitude returns close to that elicited by the $23 \mathrm{kHz}$ tone alone. At the 


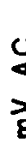

0
$E$
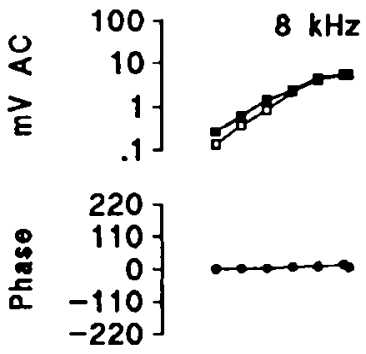

$11 \mathrm{kHz}$
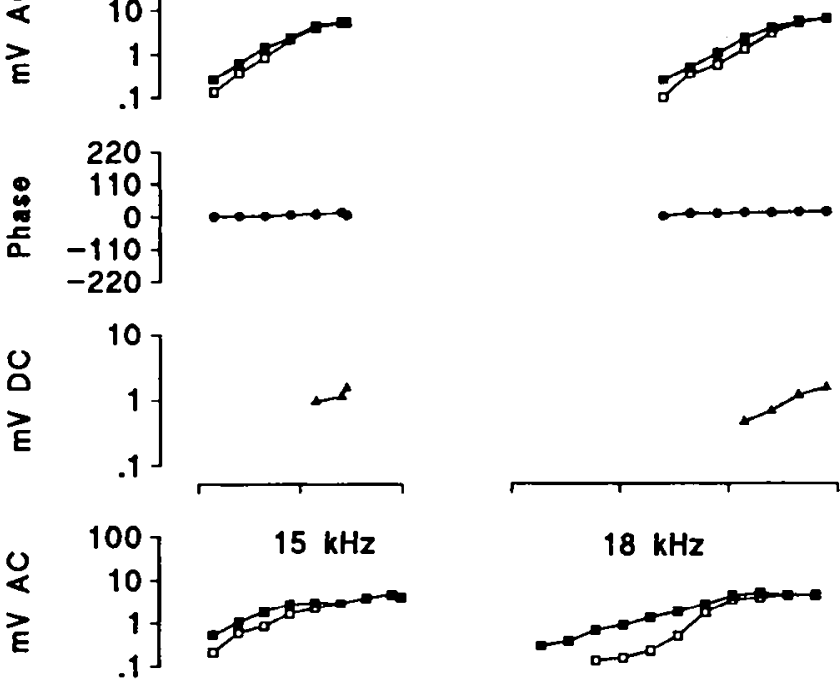

$18 \mathrm{kHz}$
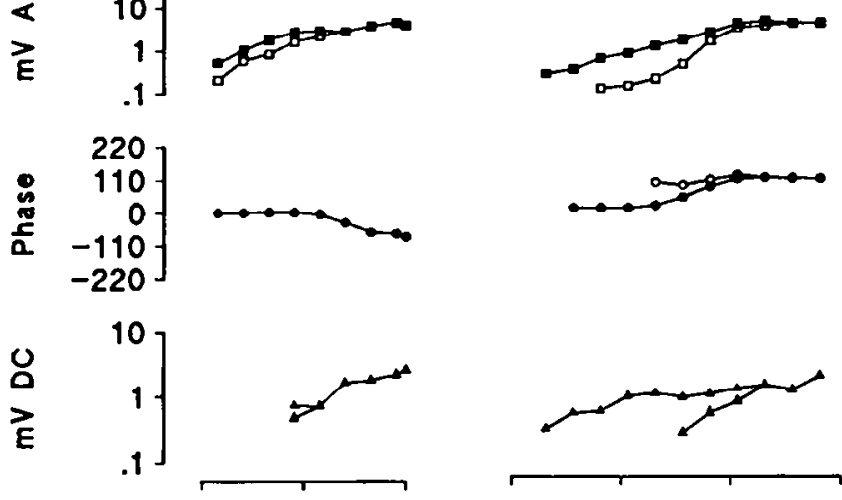

11. Magnitude, phase, and DC response/level functions based on extracellular recordings close to an IHC at the frequencies indicated. The magnitude of the $\mathrm{AC}$ response is corrected by $6 \mathrm{~dB}$ /octave from $4 \mathrm{kHz}$ to compensate for the low-pass filtering due to the recording system. The curves are arranged as in Figure 9 \begin{tabular}{rr} 
& 100 \\
\hline & 10 \\
$\vec{E}$ & 1 \\
& .1
\end{tabular}
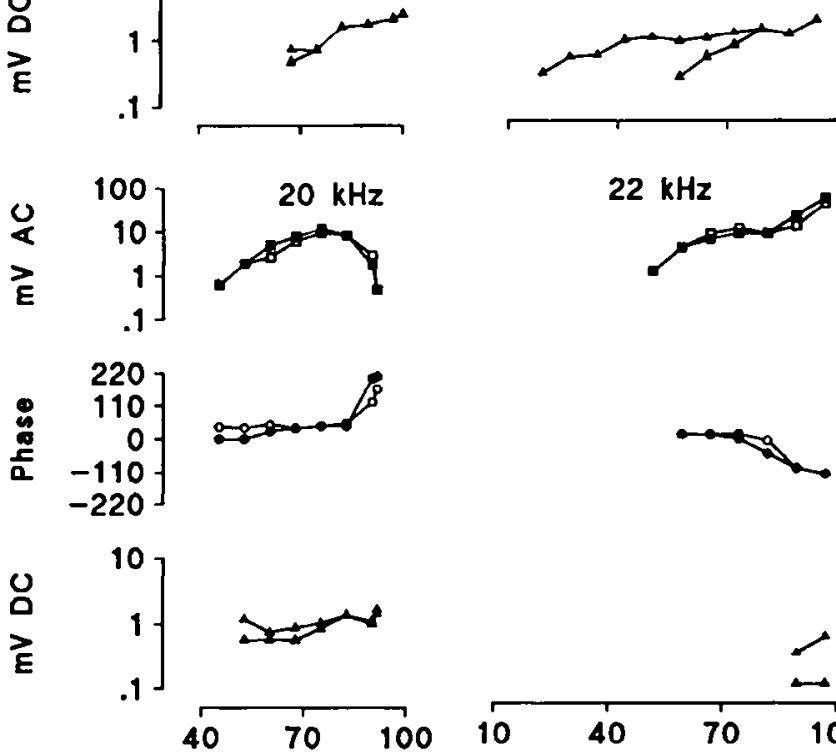

$22 \mathrm{kHz}$
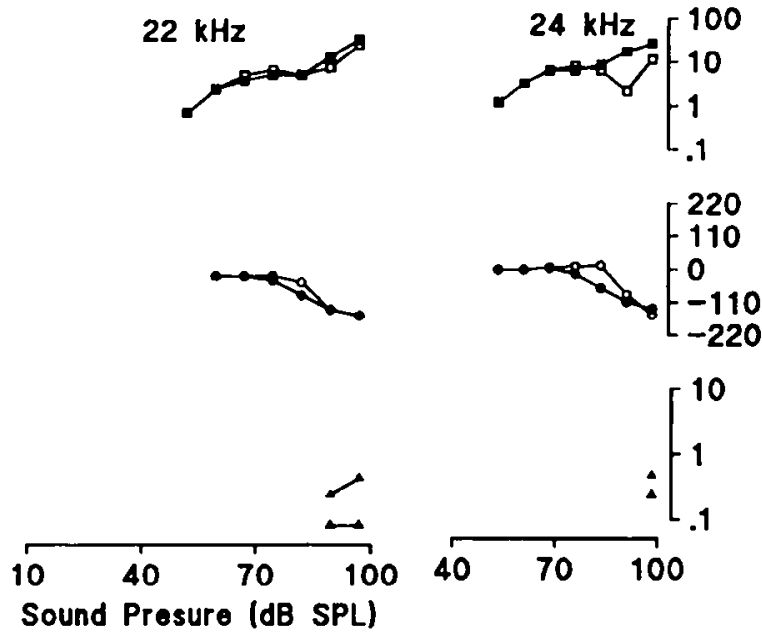

offset of the $100 \mathrm{~Hz}$ tone, the phase of the $\mathrm{AC}$ response jumps back $180^{\circ}$ to the initial value; the magnitude of the $A C$ response is totally suppressed for a duration of $11 \mathrm{msec}$ and then returns to the initial level. This phenomenon was observed for highlevel tones at frequencies between one-third and one-half an octave above the $\mathrm{CF}$ of the recording site in most preparations (a total of 47) in this series of experiments.

Enhancement, rather than suppression, by the $100 \mathrm{~Hz}$ tone of the $\mathrm{AC}$ response also occurs at frequencies about one-half an octave above the $\mathrm{CF}$, when a clcar minimum notch appears in the AC/level function (see, e.g., $24 \mathrm{kHz}$ in Figs. 3, 7, 9, 11; 25 $\mathrm{kHz}$ in Fig. 10). At these frequencies, the shape of the $\mathrm{AC} /$ level function is very sensitive to the simultaneous presentation of the low-frequency tone. At $24 \mathrm{kHz}$ (Fig. 9) the $100 \mathrm{~Hz}$ tone causes an augmentation of the low-level AC response. At high levels of the $24 \mathrm{kHz}$ tone, the $100 \mathrm{~Hz}$ tone suppresses the $\mathrm{AC}$ response and causes it to phase lag. The net effect of this differential, level-dependent action of the $100 \mathrm{~Hz}$ tone on the $\mathrm{AC}$ response is to convert the triphasic $\mathrm{AC} /$ level function into a monotonic function. By comparison, the $24 \mathrm{kHz}$. AC/level function shown in Figure 11 is essentially a monotonic function that is converted to a triphasic function by the differential action of the $100 \mathrm{~Hz}$ tone on low- and high-level responses of the AC component. These observations reveal that the monotonic and triphasic $\mathrm{AC} / \mathrm{level}$ functions to tones above the $\mathrm{CF}$ are relatively unstable and interchangeable functions. This is further illustrated in the $\mathrm{AC} /$ level functions shown in Figure 13, which are from another $\mathrm{OHC}$ in response to tones above the $\mathrm{CF}$, where 
B

$97.6 \mathrm{~dB}$ SPL, $23 \mathrm{kHz}$
A

$67.2 \mathrm{~dB}$ SPL, $13 \mathrm{kHz}$
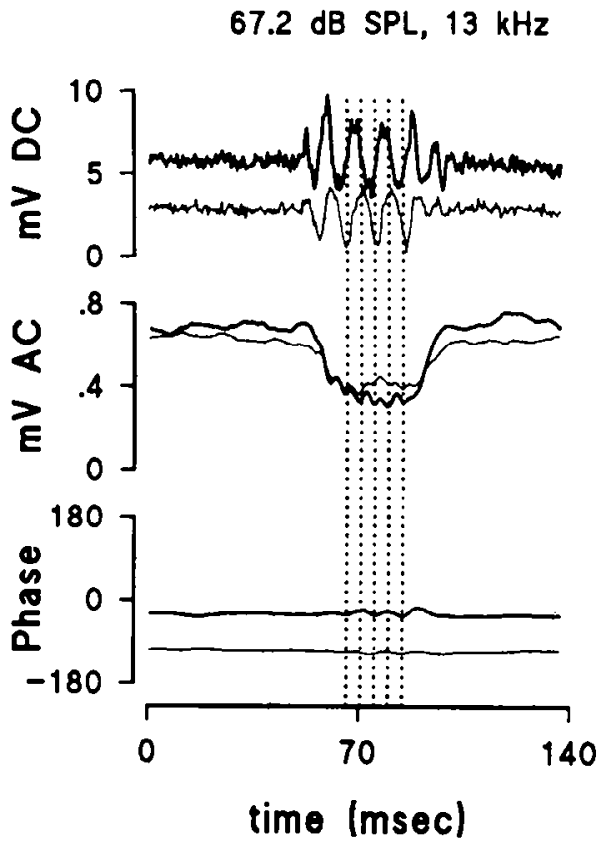

it is apparent that the $\mathrm{AC} /$ level functions obtained in response to toncs at $23 \mathrm{kHz}$ and $24 \mathrm{kHz}$ (approximately onc-half an octave above the $16 \mathrm{kHz} \mathrm{CF}$ ) become almost interchangeable through the level-dependent action of the $100 \mathrm{~Hz}$ tone.

\section{Discussion}

\section{Suppression of $O H C A C$ responses to $H F$ tones}

There is increasing, but indirect, evidence to show that, at sound levels below saturation of the $\mathrm{OHC}$ transducer, IHC and $\mathrm{OHC}$ voltage responses are governed through rapid $(\mathrm{AC})$ electromechanical feedback by the OHCs. Furthermore, on the basis of measurements of the cochlear microphonics to low-frequency tones following intense pure tone stimulation, it has been proposed that the feedback is directly related to the amplitude of the transducer current (Patuzzi et al., 1989). From studies of receptor potentials recorded from OHCs in culture, the steepest slope of the transducer function (receptor potential as a function of hair bundle displacement) and the point of maximum gain occur when the DC component of the $\mathrm{OHC}$ response is minimal (Russcll et al., 1986; Kössl and Russell, 1992). It has been suggested that the $\mathrm{DC}$ component of the $\mathrm{OHC}$ voltage response to $\mathrm{HF}$ tones could be minimized by a DC component in the electromechanical feedback to the cochlear partition (Russell et al., 1986; Russell and Kössl, 1991). Indeed, from studies of outer haircell electromotility in vitro, a nonlinear and metabolically labile DC component of the electromotility has been measured (Evans et al., 1989, 1991) with characteristics similar to those of nonlinear $\mathrm{DC}$ voltage responses of $\mathrm{OHCs}$ that have been
A
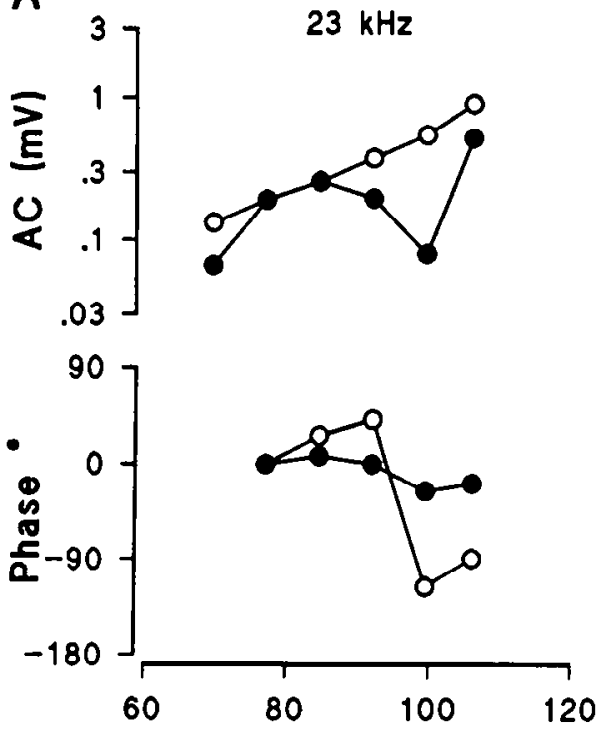

Sound Pressure (dB SPL)
B
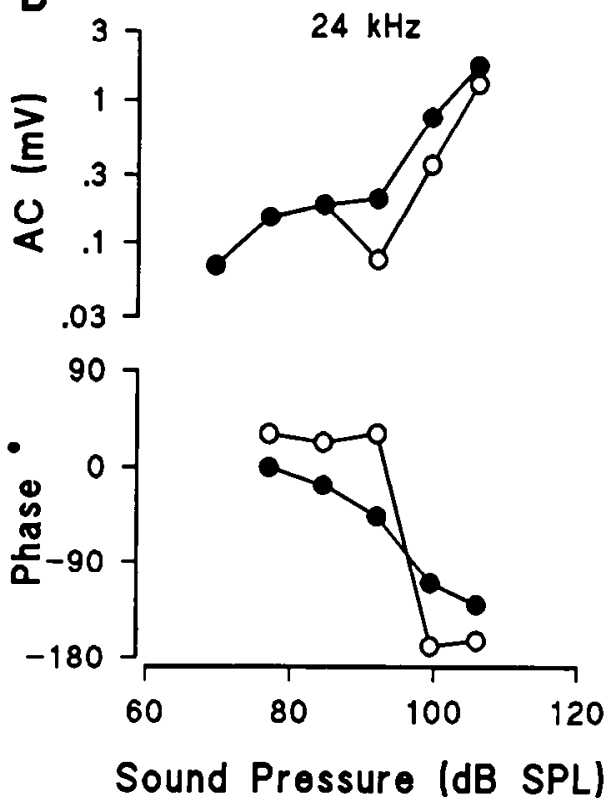

Figure 13. Intracellular recordings from an OHC to $23 \mathrm{kHz}$ and $24 \mathrm{kHz}$ tones. In each panel the magnitude of the $A C$ response (upper curves) and the phase of the AC response (middle curves) is plotted as a function of tone level. Solid symbols represent the response to the HF tone alone; open symbols represent the response to the combined 100 $\mathrm{Hz}, 80 \mathrm{~dB}$ SPL tone and HF tone. The magnitude of the $A C$ response has been compensated for the low-pass filtering of the recording electrode $(3.5 \mathrm{kHz})$ but not for the OHC membrane time constant $(0.2 \mathrm{msec})$. Resting membrane potential of $\mathrm{OHC},-65 \mathrm{mV}$; detection threshold at CF (18 kHz), $25 \mathrm{~dB}$ SPL. 
measured in the intact cochlea (Dallos et al., 1982; Russell et al., 1986). The nonlinearity of the DC component of electromotility is, itself, very sensitive to changes in the OHC membrane potential (Evans et al., 1991) and may provide the means to minimize DC voltage responses and to optimize the gain of the feedback. Thus, any displacement of the operating point of the $\mathrm{OHC}$ transducer away from the position of maximum sensitivity would reduce the gain of the transducer and hence the feedback. It is suggested here that the suppression of low-level AC responses by biasing of the basilar membrane with a $100 \mathrm{~Hz}$ tone when the basilar membrane was displaced toward scala tympani and scala vestibuli, and to a smaller extent at zero crossing (see Figs. 11,12), may be due to changes in the gains of transduction and feedback rather than through saturation of the OHC transducer conductance. This is because the HF AC responses were attenuated maximally at low levels of the HF tone when the combined levels of the $100 \mathrm{~Hz}$ and $\mathrm{HF}$ tone are below the level of saturation of the transducer conductance. Suppression is reduced when the HF AC response is saturated and begins to disappear with the appearance of the OIIC DC response to the HF tone and the associated decline in the amplitude of the OHC voltage response to the $100 \mathrm{~Hz}$ tone (see Figs. 10, 11).

\section{Suppression of $I H C D C$ responses to $H F$ tones}

It is generally accepted that stimulation of the IHCs and hence their responses to tones is mediated through sensory-motor interactions between the OHCs and the major structural elements of the cochlear partition (Mountain, 1980; Siegel and Kim, 1982; Brown and Nuttall, 1984; Liberman and Dodds, 1984; Ruggero and Rich, 1991; see Dallos, 1988, for a review). On the basis of this concept of sensory transduction in the cochlea, it is suggested that the suppression of the IHC responses to $\mathrm{HF}$ tones at frequencies around $\mathrm{CF}$ by the $100 \mathrm{~Hz}$ tone is due primarily to changes in the mechanical input to the OHCs that are brought about as a consequence of the suppression of the $\mathrm{OHC} \mathrm{AC}$ responses by the $100 \mathrm{~Hz}$ tone. For low-level tones (below about $70 \mathrm{~dB}$ SPL) at frequencies around CF, the IHC $\mathrm{DC} /$ level functions and $\mathrm{OHC} \mathrm{AC} /$ level functions share similar characteristics (Figs. 3, 7, 10, 11; Kössl and Russell, 1992) and suppression of the $\mathrm{OHC} A C$ response and IHC DC responses by the $100 \mathrm{~Hz}$ tone are very similar (see Fig. 11). That is, the IHC DC responses are suppressed by displacements both toward and away from scala tympani and to a lesser extent at the zero crossing point of basilar membrane motion (Figs. 6, 12). These observations are similar to those reported by Patuzzi and Sellick (1984), who measured intracellular AC and DC responses from IHCs to combinations of intense $40 \mathrm{~Hz}$ and HF tones. They differ slightly in that Patuzzi and Sellick observed a stronger suppression for basilar membrane displacements toward scala tympani. At frequencies more than about $3 \mathrm{kHz}$ below $\mathrm{CF}$, the $\mathrm{OHC}$ AC/level functions are more sensitive than the IHC DC/ level functions (Figs. 9, 10, 11; Kössl and Russell, 1992). At these frequencies, the $\mathrm{OHC} \mathrm{AC}$ responses are suppressed by the $100 \mathrm{~Hz}$ tones at levels below those that elicit IHC DC responses. At the levels ( $>70 \mathrm{~dB}$ SPL) when IHC DC responses first appear, the suppressive influence of the $100 \mathrm{~Hz}$ tone on the $\mathrm{OHC} \mathrm{AC}$ response (and hence on the IHC DC response) is no longer apparent. In contrast to the findings reported here, Patuzzi and Sellick (1984) discovered that IHC DC and AC responses were suppressed by basilar membrane displacements toward scala vestibuli for $\mathrm{HF}$ tones below $\mathrm{CF}$ for levels of the $\mathrm{HF}$ tone within
$20 \mathrm{~dB}$ of the threshold of the response. However, the level of the $40 \mathrm{~Hz}$ tone used by Patuzzi and Sellick was $102 \mathrm{~dB}$ SPL and is likely to produce a greater suppression than the $80 \mathrm{~dB}$ SPL $100 \mathrm{~Hz}$ tone used in these experiments. At frequencies above $\mathrm{CF}$, the IHC DC responses to the HF tone may be suppressed. This is because at some frequencies above $C F$, highlevel rather than the low-level $\mathrm{AC}$ responses are suppressed by the $100 \mathrm{~Hz}$ tone (see Figs. 10,11, 13).

\section{Suppression of voltage responses to $100 \mathrm{~Hz}$ tones}

The $\mathrm{HF}$ and $100 \mathrm{~Hz}$ tones can have reciprocal interaction in the cochlea in that the responses to the HF tone can influence the amplitude and waveform of the $100 \mathrm{~Hz}$ response. This interaction occurs at levels of the HF tone at which the OHC AC response begins to saturate and the $\mathrm{OHC} D C$ response begins to appear (see Figs. 1, 3, 4). At these levels of the HF tone, the IHC and $\mathrm{OHC} 100 \mathrm{~Hz}$ responses are both reduced in amplitude and become more symmetrical as a consequence of selective attenuation of the depolarizing phase of the IHC response and the hyperpolarizing phase of the OHC response. Patuzzi and Sellick (1984) also observed suppression of the extracellularly recorded responses to the $40 \mathrm{~Hz}$ tone by $\mathrm{HF}$ tones at frequencies below but not at the CF. The levels of the CF tones they used in their experiments were less than $70 \mathrm{~dB}$ and thus below those that we have observed to cause suppression in the experiments reported here. Similar changes in the amplitude and waveform of hair cell receptor potentials have been observed in the responses of IHCs and OHCs to low-frequency tones following exposure to brief intense tones (Cody and Russell, 1985, 1988) and during brief hypoxia and reduction in the endocochlear potential (Russell and Cowley, 1983). In the light of recent experiments that have demonstrated a nonlinear DC component of electromotility of OHCs in vitro that is vulnerable to small (3-8 $\mathrm{mV}$ ) changes in transmembrane potential and to excessive stimulation (Evans et al., 1991), it is tempting to attribute the changes reported here in the amplitude and waveform of the $\mathrm{IHC}$ and $\mathrm{OHC}$ responses to the $100 \mathrm{~Hz}$ tone to changes in the $\mathrm{DC}$ component of the $\mathrm{OHC}$ motility. It is suggested on the basis of the experiments reported here and in earlier studies (e.g., Russell and Cowley, 1983; Cody and Russell, 1985), that the responses of OHCs to low-frequency tones reflect not only forward transduction but also elements of electromotility.

The reversal of the OHC $100 \mathrm{~Hz}$ response at very high levels of the HF tone coincides with reversal of the phase of the HF $\mathrm{AC}$ response and accords with measurements $\mathrm{CM}$ in the gerbil cochlea, which also shows phase reversal at these stimulus levels (Zwislocki, 1988). The phase reversal of the $100 \mathrm{~Hz}$ response may be due to changes in the mechanical coupling between the tectorial membrane and basilar membrane caused by a reduction in rotational stiffness of the $\mathrm{OHC}$ stereocilia as a consequence of the high-level HF tone. Level-dependent changes in the stiffness of sensory bundlcs in cochlear hair cells have been measured in vitro (Saunders and Flock, 1986; I. J. Russell and M. Kössl, unpublished observations), and level-dependent changes in stiffness of the OHC stereocilia form the basis of models that attempt to explain the phase reversal of hair cell receptor potentials to intense low-frequency tones (Mountain and Cody, 1988).

At CF, suppression of the $\mathrm{OHC} 100 \mathrm{~Hz}$ response occurs at higher levels of the HF tone than at frequencies below CF (see Fig. 1 and Patuzzi and Sellick, 1984). For a given sound level above threshold for generating OHC DC potentials, the DC 
potentials generated at the $\mathrm{CF}$ are many times smaller than those generated at frequencies below the CF (see Figs. 1, 3). The smaller OHC DC responses and increased threshold for suppression of the $100 \mathrm{~Hz}$ tone that have been measured at the CF may indicate that, at the $\mathrm{CF}$, tonic forces exerted by the OHCs are more effectively translated into shear displacement between the tectorial membrane and the cuticular plate rather than as displacement of the $\mathrm{OHC}$ stereocilia, and hence displacement of the transducer operating point (Kössl and Russell, 1992).

\section{Level- and frequency-dependent interaction in $\mathrm{OHC}$ voltage} responses to tones at frequencies above $C F$ and a $100 \mathrm{~Hz}$ tone

One hypothesis that is put forward here is that, through a $\mathrm{DC}$ component of electromechanical feedback, OHCs regulate the gain of the electromechanical feedback to the cochlear partition. The effective gain and polarity of the feedback delivered to the cochlear partition have been suggested to depend on the resonant characteristics of the basilar membrane-tectorial membrane-OHC complex (Allen, 1990; Zwislocki, 1990; Kössl and Russell, 1992). Thrce further observations are reported in this article to support this hypothesis. The first is that at some frequencies above the CF, the magnitude/level functions at the tip of the secondary peaks that appear on the HF slope of the $\mathrm{OHC}$ AC tuning curve (Kössl and Russell, 1992) are very labile, and this lability is made apparent by the presence of the $100 \mathrm{~Hz}$ tone. For example, in Figure 9, the OHC AC response to the $24 \mathrm{kHz}$ tone alone is a triphasic function that changes, in the presence of the $100 \mathrm{~Hz}$ tone, to a monotonic function as a consequence of level-dependent augmentation and suppression of the $\mathrm{HF}$ response. Conversely, the magnitude/level functions of the $\mathrm{OHC} \mathrm{AC}$ responses at $24 \mathrm{kHz}$ shown in Figure 11 are monotonic functions that are converted to a triphasic function by the action of the $100 \mathrm{~Hz}$ tone. In Figure 13 the AC/level functions at $23 \mathrm{kHz}$ and $24 \mathrm{kHz}$ become almost interchangeable through the action of the $100 \mathrm{~Hz}$ tone. The presence of leveldependent notches in the magnitude/level functions and associated phase jumps have been observed in the fundamental/ level functions of IHC receptor potentials recorded in the apical turns of the cochlea (Dallos and Cheatham, 1989) and in OHCs in the basal turn as reported here and elsewhere (Kössl and Russell, 1992). These level-dependent characteristics accord with models of cochlear transduction where the mechanical coupling between the radial motion of the tectorial membrane and basilar membrane displacement is nonlinear and is influenced by electromechanical feedback by the OHC (e.g., Davis, 1983; Mountain et al., 1983). Any change in, for example, the rotational stiffness of the $\mathrm{OHC}$ hair bundles and in the transverse stiffness of the cochlear partition due to changes in the electromechanical feedback may be expected to have dramatic effects on the phase and magnitude of the AC component as functions of level, particularly at the resonance of the tectorial membrane-OHC complex.

At some levels of HF tones at frequencies above $C F$, it is possible to record large phase changes without an apparent magnitude change in the $\mathrm{AC}$ response in the presence of the $100 \mathrm{~Hz}$ tone (Fig. 13B). However, closer scrutiny of the response reveals that $\mathrm{AC}$ response is totally suppressed, without a phase change, at the onset of the $100 \mathrm{~Hz}$ tone. Eleven milliseconds later, the phase of the AC response reverses through $180^{\circ}$ and the magnitude returns to the original level. At the offset of the $100 \mathrm{~Hz}$ tone, the AC response is again totally suppressed; $11 \mathrm{msec}$ later the phase reverses back to its original polarity and the magnitude of the $\mathrm{AC}$ response returns to the original level. Thus, it appears that at these frequencies and levels, the OHC response characteristics are poised between two stable states separated by an unstable state (consider a cricket) and that the action of the 100 $\mathrm{Hz}$ tone is to switch them between these two stable states. In one of the states, the OHCs are depolarized by displacements of the basilar membrane toward scala tympani, and in the other the OHCs are depolarized by displacements toward scala vestibuli. Changes in the rotational stiffness of the $\mathrm{OHC}$ stereocilia, or perhaps their angle of attachment to the tectorial membrane, could bring about a change in the phase of OHC excitation (Zwislocki, 1988).

Further evidence that DC forces produced by OHCs may indeed control the operating point of the $\mathrm{OHC}$ transducer, and hence the effectiveness of feedback from $\mathrm{OHCs}$ on the responses of IHCs, is seen in Figure 9, where the $100 \mathrm{~Hz}$ responses of an IHC recorded from an insensitive preparation are enhanced with the appearance of DC responses to a simultaneously presented $\mathrm{HF}$ tone, with greatest enhancement occurring at CF. In this case it is suggested that the DC component of the receptor potential results in the production of DC forces by the OHCs, which cause a shift in the operating point of the $\mathrm{OHC}$ transducer to a more sensitive region of the operating function.

\section{Comparison with two-tone suppression}

The suppression caused by the low-frequency tone on the responses of hair cells to the HF tone closely resembles two-tone suppression (Galambos and Davis, 1944; Sachs and Kiang, 1968; Arthur et al., 1971). The effects of the suppression include a lateral displacement and a change in slope of the response/level function, particularly at the CF. The magnitude of the shift of the response/level function corresponds to the extent of the compressive region of the $\mathrm{OHC} \mathrm{AC/level} \mathrm{functions} \mathrm{(Figs.} \mathrm{3,} \mathrm{10,}$ 11) and IHC AC and DC/level functions (Fig. 7). Similar shifts can be deduced from isoresponse/frequency functions during two-tone suppression that have been published for hair cells in the basal (Sellick and Russell, 1979) and apical (Cheatham and Dallos, 1989; Dallos and Cheatham, 1990) turns of the guinea pig cochlea. IHC voltage responses are communicated to the brainstem via impulse traffic in the auditory nerve fibers and hence any shift and change in slope of the response/level functions will have significance for the way in which afferent fiber rate/level functions are altered during two-tone suppression. This possibility has already been raised to account for the difference between low-threshold, high-spontaneous-rate fibers and high-threshold, low-spontaneous-rate fibers to two-tone suppression (Sokolowski et al., 1989; Delgutte, 1990). The rate/ level functions of the former are displaced without a slope change during two-tone suppression. This would occur if the dynamic range of these fibers is limited by the saturation of the synaptic transmission and the impulse generating mechanism of the fiber and if the dynamic range is confined to the lincar portion of the IHC response/level functions (e.g., below about $30 \mathrm{~dB}$ SPL; Fig. 7), which are also displaced without a change in slope. Rate/ level functions of high-threshold fibers are displaced and the slope becomes changed from less than unity to a linear slope during two-tone suppression. This might be expected if the dynamic range of these fibers is limited to the compressive region of the IHC response/level function (e.g., 30-70 dB SPL; Fig. 7), where suppression effectively eliminates the compressive region of the response function, thereby effecting a slope change that will be transmitted to the rate/level function of the fiber. If the 
mechanical input to the IHCs is determined by interaction between OHCs and the cochlear partition (e.g., Davis, 1983), then it is interesting to compare the effects of two-tone suppression on the vibration of the basilar membrane (Rhode, 1977; Patuzzi et al., 1984; Robles et al., 1988) with the suppression of $\mathrm{OHC}$ responses by low-frequency tones described here. Robles et al. (1988) measured the effect of a suppressor tone at frequencies above the CF on the slope of the basilar membrane vibration amplitude as a function of level at the CF in the chinchilla cochlea. They found that during two-tone suppression, the function was displaced and that the slope changed from less than unity to a linear function. In fact, the changes illustrated in Robles et al. (1988), their Figure 2, are very similar to those described in this article for changes in the $\mathrm{OHC} \mathrm{AC/level} \mathrm{func-}$ tion during suppression by the $100 \mathrm{~Hz}$ tone, thereby lending weight to the concept that the mechanical properties of the basilar membrane are intimately linked to the responses of the OHCs. It has been asserted that two-tone suppression is not equivalent to a simple attenuation of the signal to the hair cells (Cheatham and Dallos, 1989). Evidence that justifies this assertion is based on level- and frequency-dependent phase measurements of IHC voltage responses to pure tones and combinations of tones. Attenuation of the input signal from a high to a low level is associated with a phase lead for frequencies below $\mathrm{CF}$, little phase change at $\mathrm{CF}$, and a phase lag above CF (Cheatham and Dallos, 1989). Similar level- and frequency-dependent phase changes with attenuation may be deduced from the phase measurements of $\mathrm{OHC} \mathrm{AC}$ responses in the basal turn of the guinea pig cochlea (Kössl and Russell, 1992; Figs. 3, 9-11). In contrast, two-tone suppression introduces a phase lag for frequencies below CF, a lead above CF, and either a small lag or lead at CF for IHCs in the apical turns of the cochlea (Cheatham and Dallos, 1989). Low-frequency suppression of the $\mathrm{AC}$ responses of OHCs at the $\mathrm{CF}$ in the basal turn of the cochlea was consistently associated with a phase lead that asymptotes to about $90^{\circ}$ (based on measurements from 22 prcparations). The level- and suppression-induced phase of IHC AC responses at $\mathrm{CF}$ were found to be more variable than those of the OHCs. In five preparations, suppression and increases in level were associated with a phase lead, and in three preparations suppression was associated with a phase lag. The $\mathrm{AC}$ responses of the $\mathrm{IHC}$ represented in Figure 7 undergo a small lag that reverses to a lead when the level of the $C F$ tone exceeds the compressive region of the AC/level function (about $67 \mathrm{~dB}$ SPL; Fig. 7). By comparison, two-tone suppression is associated with a small phase lag in the phase of basilar membrane motion measured in the chinchilla (Robles et al., 1988) and in spike activity of auditory fibers in the cat during two-tone suppression (Deng and Geisler, 1984). However, on the basis of a relatively large population of measurements Deng and Geisler found variability in associating suppression with either lags, leads, or no change in phase between fibers and preparations. In conclusion, the characteristics of two-tone suppression are similar in their manifestation in hair cells, afferent nerve fibers, and the basilar membrane, but there remain some differences associated with suppression-induced phase changes at the $\mathrm{CF}$.

\section{References}

Allen JB (1990) Modeling the noise damaged cochlea. In: Mechanics and biophysics of hearing (Dallos P, Geisler CD, Mathews JW, Ruggero M, Steele CR, eds), pp 324-332. New York: Springer.
Arthur RM, Pfeiffer RR, Suga N (1971) Properties of two-tone inhibition in primary auditory neurons. J Physiol (Lond) 212:593-609.

Ashmore JF (1987) A fast motile response in the guinea-pig outer hair cells: the cellular basis of the cochlear amplifier. J Physiol (Lond) 388: 323-347.

Baden-Kristensen K, Weiss TF (1983) Receptor potentials of lizard hair cells with free standing stereocilia: responses to clicks. J Physiol (Lond) 335:699-722.

Brown MC, Nuttall AL (1984) Efferent control of inner hair cell responses in the guinea pig. J Physiol (Lond) 354:625-646.

Brown MC, Nuttall AL, Master RI (1983) Intracellular recordings from cochlear hair cells: effects of stimulation of the crossed olivocochlear efferents. Science 222:69-72.

Brownell WE, Bader CR, Bertrand D, de Ribaupierre Y (1985) Evoked mechanical responses of isolated cochlear outer hair cells. Science 227:194-196.

Cheatham MA, Dallos P (1989) Two-tone suppression in inner hair cell responses. Hear Res 40:187-196.

Cody AR, Russell IJ (1985) Outer hair cells in the mammalian cochlea and noise-induced hearing loss. Nature 315:662-665.

Cody AR, Russell IJ (1987) The responses of hair cells in the basal turn of the guinea-pig cochlea to tones. J Physiol (Lond) 383:551569.

Cody AR, Russell IJ (1988) Acoustically induced hearing loss: intracellular studies in the guinea pig cochlea. Hear Res 35:59-70.

Dallos P (1988) Cochlear neurobiology: some key experiments and conccpts of the past two decades. In: Auditory function: neurobiological basis of hearing (Edelman GM, Gall WE, Cowan WM, eds), pp 153-188. New York: Wiley.

Dallos P, Cheatham MA (1989) Nonlinearities in cochlear receptor potentials in their origins. J Acoust Soc Am 86:1790-1796.

Dallos P, Santos-Sacchi J, Flock $\AA$ (1982) Intracellular recordings from cochlear outer hair cells. Science 218:582-584.

Davis H (1983) An active process in cochlear mechanics. Hear Res 9:79-90.

Delgutte B (1990) Two-tone rate suppression in auditory-nerve fibers: dependence on suppressor frequency and level. Hear Res 49:225-246.

Deng L, Geisler CD (1984) Changes in the phase of excitor-tone responses in cat auditory-nerve fibres by suppressor tones and fatigue. J Acoust Soc Am 78:1633-1643.

Evans BN, Hallworth R, Dallos P (1988) Asymmetries in motile responses of outer hair cells in simulated in vivo conditions. In: Cochlear mechanisms: structure function and models (Wilson JP, Kemp DT, eds), pp 205-206. London: Plenum.

Evans BN, Hallworth R, Dallos P (1991) Outer hair cell electromotility: the sensitivity and vulnerability of the DC component. Hear Res 52:288-304.

Evans EF (1979) Neuroleptanaesthesia for the guinea-pig: an ideal anaesthetic procedure for long term physiological studies of the cochlea. Arch Otolaryngol 105:185-186.

Galambos R, Davis H (1944) Inhibition of activity in single auditory nerve fibres by acoustic stimulation. J Neurophys 7:287-303.

Kemp DT (1978) Stimulated acoustic emissions from within the human auditory system. J Acoust Soc Am 64:1386-1391.

Kim DO, Molnar CE, Mathews JW (1980) Cochlear mechanics: nonlinear behaviour in two-tone responses and in ear-canal sound pressure. J Acoust Soc Am 67:1704-1721.

Kössl M, Russell IJ (1990) Modulation of voltage responses to 100 $\mathrm{Hz}$ tones by high frequency tones in cochlear hair cells. In: Mechanics and biophysics of hearing (Dallos P, Geisler CD, Mathews JW, Ruggero M, Steele CR, eds), pp 42-50. New York: Springer.

Kössl M, Russell IJ (1992) The phase and magnitude of hair cell receptor potentials and frequency tuning in the guinea pig cochlea. $\mathrm{J}$ Neurosci 12:1575-1586.

Liberman MC, Dodds LW (1984) Single-neuron labeling and chronic cochlear pathology. III. Stereocilia damage and alterations of threshold tuning curves. Hear Res 16:55-74.

Mountain DC (1980) Changes in endolymphatic potential and crossed olivocochlcar bundle stimulation alter cochlear mechanics. Science 210:71-72.

Mountain CD, Cody AR (1988) Mechanical coupling between inner and outer hair cells in the mammalian cochlea. In: Cochlear mechanisms: structure function and models (Wilson JP, Kemp DT, eds), pp 153-160. London: Plenum.

Mountain DC, Hubbard AE, McMullen TA (1983) Electromechanical 
processes in the cochlea. In: Mechanics of hearing (de Boer E, Viergever MA, eds), pp 119-126. Delft, The Netherlands: Delft UP.

Patuzzi R, Sellick PM (1984) The modulation of the sensitivity of the mammalian cochlea by low frequency tones. II. Inner hair cell receptor potentials. Hear Res 13:9-18.

Patuzzi R, Johnstone BM, Sellick PM (1984) The alteration of the vibration of the basilar membrane produced by loud sound. Hear Res 13:99-100.

Patuzzi R, Yates GK, Johnstone BM (1989) Outer hair cell receptor currents and sensorineural hearing loss. Hear Res 42:47-72.

Rhode WS (1971) Observations on the vibration of the basilar membrane in squirrel monkeys using the Mössbauer technique. J Acoust Soc Am 49:1218-1231.

Rhode WS (1977) Some observations on two-tone interaction measured with the Mossbauer effect. In: Psychophysics and physiology of hearing (Evans EF, Wilson JP, eds), pp 27-38. New York: Academic.

Robles L, Ruggero MA, Rich NC (1988) Nonlinear interactions in the mechanical responses of the cochlea to two tone stimuli. In: Cochlear mechanisms: structure, function and models (Wilson JP, Kemp DT, eds), pp 369-376. New York: Plenum.

Ruggero MA, Rich NC (1991) Furosemide alters organ of Corti mechanics: evidence for feedback from outer hair cells upon the basilar membrane. J Neurosci 11:1057-1067.

Russell IJ, Cowley EM (1983) The influence of transient asphyxia on receptor potentials in inner hair cells of the guinea pig cochlea. Hear Res 11:373-384.

Russell IJ. Kössl M (1991) The voltage responses of hair cells in the basal turn of the guinea-pig cochlea. J Physiol (Lond) 435:493-511.

Russell IJ, Sellick PM (1978) Intracellular studies of hair cells in the mammalian cochlea. J Physiol (Lond) 284:261-290.

Russell IJ, Cody AR, Richardson GP (1986) The responses of inner and outer hair cells in the basal turn of the guinea-pig cochlea and in the mouse cochlea grown in vitro. Hear Res 22:199-216.
Sachs MB, Kiang NYS (1968) Two-tone inhibition in auditory nerve fibers in cats: tone-burst stimuli. J Acoust Soc Am 56:1835-1847.

Santos-Sacchi J (1989) Asymmetry in voltage dependent movements of isolated outer hair cells from the organ of Corti. J Neurosci 9:29542962.

Saunders JC, Flock A (1986) Recovery of threshold shift in hair-cell stereocilia following exposure to intense stimulation. Hear Res 23 : 233-244.

Sellick PM, Russell IJ (1979) Two-tone suppression in cochlear hair cells. Hear Res 1:227-236.

Sellick PM, Patuzzi R, Johnstone BM (1982) Measurement of basilar membrane motion in the guinea pig using the Mössbauer technique. J Acoust Soc Am 61:133-149.

Siegel JH, Kim DO (1982) Efferent neural control of cochlear mechanics? Olivocochlear bundle stimulation affects cochlear biomechanical nonlinearity. Hear Res 6:171-182.

Sokolowski BHA, Sachs MB, Golstein JL (1989) Auditory nerve ratelevel functions for two-tone stimuli: possible relation to basilar membrane nonlinearity. Hear Res 41:115-124.

Weiss TF (1982) Bidirectional transduction in vertebrate hair cells: a mechanism for coupling mechanical and electrical processes. Hear Res 7:353-360.

Wilson JP, Johnstone JR (1975) Basilar membrane and middle ear vibration in guinea pig measured by capacitive probe. J Acoust Soc Am 57:705-723.

Zwislocki JJ (1988) Phase reversal of OHC response at high sound intensities. In: Cochlear mechanisms: structure function and models (Wilson JP, Kemp DT, eds), pp 163-168. London: Plenum.

Zwislocki JJ (1990) Active cochlear feedback: required structure and response phase. In: Mechanics and biophysics of hearing (Dallos P, Geisler CD, Mathews JW, Ruggero M, Steele CR, eds), pp 114-120. New York: Springer. 